Article

\title{
In Situ Hybridization of Pulp Fibers Using Mg-Al Layered Double Hydroxides
}

\author{
Carl-Erik Lange ${ }^{1, *}$, Mika Lastusaari ${ }^{2,3}$, Mehedi Reza ${ }^{4}$, Seyed Kourosh Latifi ${ }^{5}$, Pasi Kallio ${ }^{5}$ \\ and Pedro Fardim 1 ,* \\ ${ }^{1}$ Department of Chemical Engineering, Åbo Akademi University, Porthansgatan 3-5, \\ FI-20500 Åbo, Finland \\ ${ }^{2}$ Department of Chemistry, University of Turku, FI-20014 Turun Yliopisto, Finland; \\ E-Mail: miklas@utu.fi \\ ${ }^{3}$ Turku University Centre for Materials and Surfaces (MatSurf), FI-20014 Turun Yliopisto, Finland \\ ${ }^{4}$ Department of Applied Physics, Aalto University School of Science, FI-00076 Aalto, Finland; \\ E-Mail: mehedi.reza@aalto.fi \\ ${ }^{5}$ Department of Automation Science and Engineering, Tampere University of Technology, \\ Korkeakoulunkatu 3, FI-33720 Tampere, Finland; E-Mails: kourosh_latifi@ hotmail.com (S.K.L.); \\ pasi.kallio@tut.fi (P.K.)
}

* Authors to whom correspondence should be addressed; E-Mails: clange@ abo.fi (C.-E.L.); pfardim@abo.fi (P.F.); Tel.: +358-2-2154237 (C.-E.L.); +358-50-4096424 (P.F.).

Academic Editor: Noureddine Abidi

Received: 27 February 2015 / Accepted: 13 April 2015 / Published: 29 April 2015

\begin{abstract}
Inorganic $\mathrm{Mg}^{2+}$ and $\mathrm{Al}^{3+}$ containing layered double hydroxide (LDH) particles were synthesised in situ from aqueous solution onto chemical pulp fibers of pine (Pinus sylvestris). High super saturated (hss) solution with sodium carbonate produced LDH particles with an average diameter of 100-200 nm. Nano-size $(70 \mathrm{~nm}) \mathrm{LDH}$ particles were found from fibers external surface and, to a lesser degree, from the S2 cell wall after synthesis via low super saturated $(l s s)$ route. The synthesis via slow urea hydrolysis (Uhyd) yielded micron and clay sized LDH $(2-5 \mu \mathrm{m})$ and enabled efficient fiber densification via mineralization of S2 fiber wall layer as indicated by TEM and compliance analysis. The Uhyd method decreased fiber compliance up to $50 \%$. Reduction in the polymerisation degree of cellulose was observed with capillary viscometry. Thermogravimetric analysis showed that the hybridization with $\mathrm{LDH}$ reduced the exothermic heat, indicating, that this material can be incorporated in flame retardant applications. Fiber charge was assessed by
\end{abstract}


adsorption expermients with methylene blue (MB) and metanil yellow (MY). Synthesis via lss route retained most of the fibres original charge and provided the highest capacity $(10 \mu \mathrm{mol} / \mathrm{g})$ for anionic MY, indicating cationic character of hybrid fibers. Our results suggested that mineralized fibers can be potentially used in advanced applications such as biocomposites and adsorbent materials.

Keywords: combustion; compliance; flexibility; FTIR; kraft; mineralization; pine; pulp; SEM; TEM

\section{Introduction}

A great deal of research that concentrates on layered double hydroxide (LDH) particles is related to composite structures with various polymeric matrices $[1,2]$ and sorption processes for water purification applications [3,4], but also to coating technology, especially in corrosion protection [5-7], and to different catalytic processes [8,9]. Electrochemical applications, such as batteries [10], capacitors [11] and electrodes [12], in which thin film structures are important [5], are of interest, as well. Some studies have emerged around the pulp and paper industry. Applications that involve packaging materials [13-15], bleaching [16], filler formulation [17] and lignin depolymerization [18] are being devised. Many of these research fields require material scientists to expand the LDH structure beyond the simple hydrotalcite (HT) that is comprised of $\mathrm{Mg}^{2+}$ and $\mathrm{Al}^{3+}$ hydroxides and $\mathrm{CO}_{3}^{2-}$ as a counter balancing ion residing within the interlamellar gallery. Other synthesized natural-like minerals that are included in the hydrotalcite group are the ones where $\mathrm{Mg}^{2+}$ is replaced by $\mathrm{Zn}^{2+}$ [19-21] as in zaccagnaite or by $\mathrm{Ni}^{2+}$ [22,23] as in takovite. Trivalent aluminum may be replaced by $\mathrm{Fe}^{3+}$ [24,25] as in pyroaurite or reevesite. Furthermore, post-synthetic processing of $\mathrm{LDH}$ is often applied to facilitate desirable properties. These processes include calcination, anion exchange, reconstruction and exfoliation $[1,8,26]$.

Considering the synthesis, the nucleation kinetics in high supersaturated solution ( $h s s$ ) generally produces LDH particles with lower crystallinity, since the number of nucleation sites is at the maximum in the given system and the $\mathrm{pH}$ changes strongly at the beginning of synthesis [27]. In low supersaturated solution (lss) conditions, the crystal growth surpasses nucleation. Slow titration provides nano-sized particles and better formed crystals, due to continuous $\mathrm{pH}$ control. The size of inorganic particles that are synthesized in aqueous solution can be affected via post-synthetic hydrothermal treatment. Elevated temperature and pressure allows cations to migrate slowly in the crystalline structure of an LDH. For example, the slow urea hydrolysis (Uhyd) produces micron-sized particles due to an ammonia-induced slow pH increase [20]. Since LDH particles are known for their memory effect upon calcination and being capable of exchanging gallery ions in order of stability, faults and perturbations in the crystalline structure may allow the particles to remain active, even if carbonate is being introduced into the lattice during the synthesis.

For any engineered application where wood fibers are deployed, it is important to understand the changes in their fundamental characteristics during processing. We have previously shown how the surface chemistry of fibers can be changed with LDH and how these fibers behave in injection molded 
composite structures [28,29]. In this article, we address the chemical and physical characteristics of pulp fibers considering the changes in cellulose polymer chain length, adsorption capacity, thermal behavior and compliance after the $l s s$, hss and Uhyd synthesis routes, which all involve in situ LDH particle synthesis on fiber surfaces. To our surprise, the Uhyd synthesis was able to mineralize the fibers, as well.

\section{Experimental Section}

\subsection{Materials}

Chemicals that were supplied by Sigma-Aldrich (Saint Louis, MO, USA) include aluminium nitrate $\left(\mathrm{Al}\left(\mathrm{NO}_{3}\right)_{3} \cdot 9 \mathrm{H}_{2} \mathrm{O}, \geq 98 \%\right.$, Germany), hydrotalcite $(\mathrm{HT})$ that was used as a reference LDH $\left(\mathrm{Mg}_{6} \mathrm{Al}_{2}\left(\mathrm{CO}_{2}\right)(\mathrm{OH})_{16} \cdot 4 \mathrm{H}_{2} \mathrm{O}\right.$, USA) magnesium nitrate $\left(\mathrm{Mg}\left(\mathrm{NO}_{3}\right)_{2} \cdot 6 \mathrm{H}_{2} \mathrm{O}, 98 \%-102 \%\right.$, UK), metanil yellow (MY) $\left(\mathrm{C}_{18} \mathrm{H}_{14} \mathrm{~N}_{3} \mathrm{O}_{3} \mathrm{SNa}\right.$, $\geq 98 \%$, Switzerland) and high purity $\mathrm{Zn}$ standard (Zn, $\geq 99.998 \%$, EU). Chemicals purchased from Merck (Kenilworth, NJ, USA) include barbital $\left(\mathrm{C}_{8} \mathrm{H}_{12} \mathrm{~N}_{2} \mathrm{O}_{3}, \geq 99 \%\right.$, Germany), sodium carbonate $\left(\mathrm{Na}_{2} \mathrm{CO}_{3}, \geq 99.9 \%\right.$, Germany), potassium chloride $\left(\mathrm{KCl}, \geq 99.5 \%\right.$, Germany) and urea $\left(\mathrm{CO}\left(\mathrm{NH}_{2}\right)_{2}, \geq 99.0 \%-100.5 \%\right.$, Germany). High purity $\mathrm{Pb}$ standard $(\mathrm{Pb}, \geq 99.998 \%$, US) was supplied by TA Instruments (New Castle, DE, USA). Analyte for methylene blue (MB) $\left(\mathrm{C}_{16} \mathrm{H}_{18} \mathrm{ClN}_{3} \mathrm{~S} \cdot \mathrm{xH}_{2} \mathrm{O}, \simeq 95 \%\right.$, Switzerland) adsorption was supplied by Ciba. MB was recrystallized from hot deionized water solution with ethanol upon cooling for removal of crystalline water. Bis(ethylenediamine)copper(II) hydroxide (CED) solution $\left(\mathrm{Cu}\left(\mathrm{NH}_{2}\left(\mathrm{CH}_{2}\right)_{2} \mathrm{NH}_{2}\right)_{2}(\mathrm{OH})_{2}, 1.0 \mathrm{M}\right.$, Finland) was purchased from FF-Chemicals (Haukipudas, FIN). Fully bleached chemical sulphate pulp (BKraft) of pine (Pinus sylvestris) was kindly provided by Metsä Fiber (Rauma Mill, Finland). All received pulp samples were stored in a freezer and used after thawing in a cooler at $283 \mathrm{~K}\left(10{ }^{\circ} \mathrm{C}\right)$. All reagents except $\mathrm{MB}$ were used without further purification.

\subsection{Methods}

\subsubsection{LDH Synthesis and Fiber Mineralization}

LDH synthesis was carried out in two stages. The precipitation stage was set up according to the chosen synthesis route, namely lss, hss or Uhyd. Two automatic titrators were applied for dispensing the reagents into distilled water in lss route. The acidic $(\mathrm{pH}=3.7)$ aqueous solution of $\mathrm{Al}\left(\mathrm{NO}_{3}\right)_{3}$ and $\mathrm{Mg}\left(\mathrm{NO}_{3}\right)_{2}$ with total metal ion concentration $\left(\mathrm{c}\left(\mathrm{M}_{\text {tot }}^{z+}\right)\right)$ equal to $0.50 \mathrm{M}$ at molar ratio $1: 2$ was dispensed from one of the titrators. The $\mathrm{pH}$ was kept close to 9.5 by dispensing $1.0 \mathrm{M} \mathrm{NaOH}$ from the other. Dispensing rate in monotonous equilibrium titration method was set to $0.33 \mathrm{~mL} \cdot \mathrm{min}^{-1}$ for both reagents. The suspension was stirred vigorously during the synthesis. Carbonate containing LDH particles was synthesised via $h$ ss route by adding calculated amount of $\mathrm{Na}_{2} \mathrm{CO}_{3}$ into the aqueous solution that contained the precipitating ions. Particle nucleation begins immediately after $\mathrm{Na}_{2} \mathrm{CO}_{3}$ is transferred into the precursors containing solution due to rapid $\mathrm{pH}$ change. LDH synthesis via Uhyd followed the hss with an exception that $\mathrm{pH}$ was controlled by slow urea hydrolysis in an autoclave. The $\mathrm{c}\left(\mathrm{M}_{\text {tot }}^{z+}\right)$ in final reaction volume $(500 \mathrm{~mL})$ in all experiments was $25 \mathrm{mM}$. The amount of added and liberated carbonate in hss and Uhyd synthesis routes, respectively, was set to $3.3 \mathrm{c}\left(\mathrm{M}_{t o t}^{z+}\right)$, which corresponded to 
twenty fold excess from the calculated amount that was required to balance the charge in LDH gallery. To advance the olation and crystallization processes in the second stage the precipiatates were transferred into $1000 \mathrm{~mL}$ reaction vessels and treated under hydrothermal conditions with autogeneous pressure built up at $393 \pm 10 \mathrm{~K}\left(120 \pm 10^{\circ} \mathrm{C}\right)$ for $48 \mathrm{~h}$. Urea was assumed to hydrolyse completely in the given conditions. Synthesised LDH were washed several times by centrifugation and concomitant solvent exchange.

Modification of pulp fibers followed the same procedures. Dry weight of applied BKraft fibers was $5.0 \mathrm{~g}$. The pulp sludge in hss and Uhyd synthesis route were allowed to soak for $90 \mathrm{~min}$ in the $\mathrm{Al}^{3+}$ and $\mathrm{Mg}^{2+}$ nitrate solution prior to hydrothermal treatment. In lss the fibers were first disintegrated in distilled water. Finally the pulp samples were thoroughly washed by repetitious filtration through a filter paper (pore size: $7-12$ microns) at maximum of $2 \%$ suspension consistency in reduced pressure until the UV-Vis analysis from the filtrates showed a change less than 0.01 absorbance units at the dispersion edge $(240 \mathrm{~nm})$. The $\mathrm{pH}$ of a final filtrate was in between 7.0 and 7.5. Then the pulp fibers were dried in an oven at $333 \mathrm{~K}\left(60^{\circ} \mathrm{C}\right)$ until constant weight. Hereafter the modified pulp fibers are referred according to the synthesis procedure (lss, hss and $U h y d$ ). Neat LDH particles are referred to LDH-OH, LDH-C and LDH-U respectively.

\subsubsection{X-Ray Diffractometry}

X-ray diffractometer (Rigaku MiniFlex-II Desktop X-ray Diffractometer) was used to record the diffraction pattern (XRD) of the neat particles. The XRD patterns were collected in the $2 \theta$ range of $2^{\circ}-40^{\circ}$ with $\operatorname{CuK} \alpha(\lambda=1.54184 \AA)$ radiation. The resolution was $0.02^{\circ}$ and the scanning speed was $2^{\circ} \min ^{-1}$. Operating voltage of the $\mathrm{X}$-ray tube was $30 \mathrm{kV}$ and the electric current was $15 \mathrm{~mA}$.

\subsubsection{ATR-FTIR}

Infrared spectrophotometer (Thermo Scientific, Nicolet iS50 FT IR, Madison, WI, USA) with attenuated total reflection (ATR) setup was used in analysis of LDH particles and modified pulp fibers at different stages of combustion. Instrument was equipped with a diamond crystal and a pressure gauge. The pressure was set to $30 \pm 2 \mathrm{~kg}$ in all samples. Total of 64 scans was recorded and corrected with the Omnic ${ }^{\circledR}$ spectral suite software that provided ambient background and ATR correction for $45^{\circ}$ incident angle with 1 refraction assuming 1.50 refractive index for all samples.

Combustion was evaluated by heating the sample to the target temperature in a muffle oven in an open porcelain crucible. 10 min conditioning was allowed for the sample that was treated at $473 \mathrm{~K}\left(200{ }^{\circ} \mathrm{C}\right)$ while the ones that were treated at higher temperatures were taken out within one minute after target temperature was reached. Temperature ramp rate was $20 \mathrm{~K} \cdot \mathrm{min}^{-1}$. In combustion kinetics the sample was heated from the ambient conditions rapidly to $613 \mathrm{~K}\left(340{ }^{\circ} \mathrm{C}\right)$. Cooling down was allowed to occur in a crucible with a lid for approximately two minutes prior to FTIR analysis. The vibration induced absorbance signals were deconvoluted by applying Gaussian fit with Origin ${ }^{\circledR} 7.5$ software. The rule for minimum number of required absorbance signals was used. 


\subsubsection{Thermogravimetry}

Thermo gravimetric analysis was performed with TA Instruments (SDT 2960, New Castle, DE, USA) apparatus. Thermographs (TG) for LDH powders were recorded by using linear $3 \mathrm{~K} \cdot \min ^{-1}$ sweep rate up to $873 \mathrm{~K}\left(600^{\circ} \mathrm{C}\right)$ under constant air flow $\left(100 \mathrm{~mL} \cdot \mathrm{min}^{-1}\right)$ in aluminium oxide cups $(60 \mu \mathrm{L})$. The weight of pristine $\mathrm{LDH}$ powder in each experiment was approximately $20 \mathrm{mg}$.

The LDH modified pulp fibers were compressed in a custom made pelletizer to cylindrical shape that was $5.0 \pm 0.1 \mathrm{~mm}$ in diameter and $0.85 \pm 0.05 \mathrm{~mm}$ in thickness. The applied pressure $\left(175 \pm 20 \mathrm{~kg} \cdot \mathrm{cm}^{-2}\right)$ and the sample weight $(10 \pm 1 \mathrm{mg})$ were optimized before TG analysis. Sample density was $600 \pm 50 \mathrm{~kg} \cdot \mathrm{m}^{-3}$. The pellets were designed to allow enough porosity for gaseous combustion products to leave the sample upon heating. The thermal history of the pulp samples was controlled with an isotherm at $473 \mathrm{~K}\left(200^{\circ} \mathrm{C}\right)$. After $10 \mathrm{~min}$ isothermal conditioning the linear sweep was allowed to continue as with $\mathrm{LDH}$ powders up to $800 \mathrm{~K}\left(527^{\circ} \mathrm{C}\right)$ where another isotherm was commenced for 10 min to stabilize the weight of residual LDH. Baseline was defined by recording the thermograph with an empty alumina cup.

\subsubsection{Microscopy}

Visual inspection of LDH modified fibers before and after TG analysis, was done with a Leo Gemini 1530 field emission scanning electron microscope that was equipped with In-Lens detector (LEO Electron Microscopy Ltd., Oberkochen, Germany). Modified samples were coated with carbon in Temcarb TB500 sputter coater (Emscope Laboratories, Ashford, UK). Optimum accelerating voltage for modified samples was $2.70 \mathrm{kV}$ and $15.0 \mathrm{kV}$ for the incinerated samples. The working distances were, respectively, 5-6 $\mathrm{mm}$ and $13-14 \mathrm{~mm}$.

For TEM experimentation, the epoxy resin-embedded sample blocks were sectioned with an ultra-microtome (Leica EM UC7) equipped with a diamond knife. Sections of $200 \mathrm{~nm}$ in thickness were picked on 600 hexagonal mesh copper grids. Ultra-thin sections were examined with an FEI Tecnai 12 transmission electron microscope at a $120-\mathrm{kV}$ accelerating voltage.

\subsubsection{Microrobotic Platform}

A microrobotic platform, the mechanics and the user interface of which were designed and developed at Tampere University of Technology, was implemented to perform the compliance experiments for individual pulp fibers. In addition, a MATLAB code was utilized to calculate the compliance from the raw data. Experimental results were tested against the null hypothesis. The $t$-test was applied to calculate the result significance. Ten fibers from each batch were forced to flex five times in our experiments, and the averaged compliances were calculated from the force sensor data. The platform and its application for pulp fiber characterization is explained by Saketi et al. [30]. In the method, a pulp fiber is gripped from both of its ends by two microgrippers (Figure 1). A force sensor is then positioned at the midpoint of the fiber's free span. The applied force $(F)$ is measured five times by setting the maximum deflection limit $\left(Y_{\max }\right)$ in meters $(\mathrm{m})$ according to the fibers linear elastic range. The extent of deflection is fixed in all experiments. For calculating the compliance, the fiber was considered as a rectangular beam with both of its ends fixed in position. It is generally known that $F$ in this particular 
case is related to $Y_{\max }$ according to Equation (1).

$$
Y_{\max }=\frac{F \cdot L^{3}}{192 \cdot E \cdot I}
$$

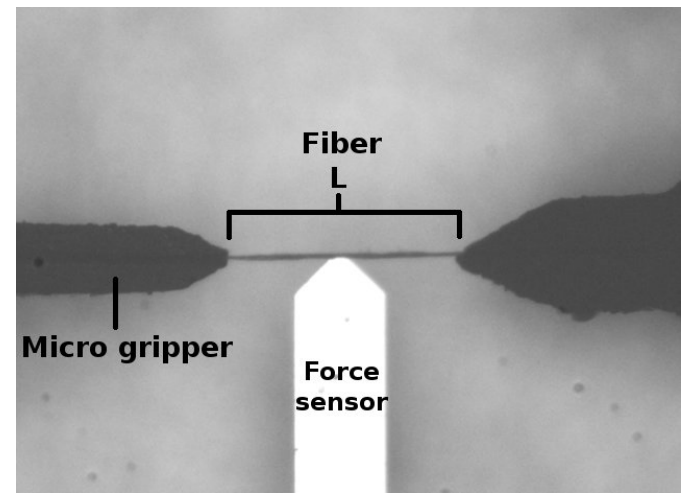

Figure 1. An image of the setup in the microrobotic platform for compliance measurement.

In the given equation, $L$ is the free length (m) of the beam, $E$ is its young modulus $\left(\mathrm{N} \mathrm{m}^{-2}\right)$, and, $I$ is its moment of inertia $\left(\mathrm{kg} \cdot \mathrm{m}^{2}\right)$. The compliance of the beam is defined as follows.

$$
\frac{1}{k}=\frac{1}{E \cdot I}
$$

The $k$ is the stiffness of the body. The Equation (1) can then be rewritten according to Equation (3), from which the $k^{-1}$ can be calculated.

$$
Y_{\max }=\frac{F \cdot L^{3}}{192 \cdot k}
$$

\subsubsection{Capillary Viscometry}

Intrinsic viscosity was determined with capillary viscometer to address the possible cellulose polymer degradation induced by LDH synthesis. The apparatus and applied method is described in the standard ISO/FDIS 5351:2009(E). The viscosity is determined by recording the time for the CED solution that contains dissolved pulp fibers to flow through a pre-determined volume in a $0.8 \pm 0.05 \mathrm{~mm}$ capillary-tube viscometer at $25{ }^{\circ} \mathrm{C}(298 \mathrm{~K})$. Calibration of the capillary-tube viscometer was performed with $65 \%$ glycerol solution that has a known viscosity $(10 \mathrm{mPa} \cdot \mathrm{s})$ at the given temperature. The CED solution was controlled by comparing the efflux time ratio for diluted CED (0.5 M) to distilled water. The value should lie in between 1.27 and 1.29 to assure the freshness of CED solution. We found the value to be 1.284. Viscometer constant was then measured with two capillary-tube viscometers and calculated according to Equation (4). The limiting viscosity number for each sample was calculated from Equation (5) by using the tabulated values set according to [31] for viscosity ratio as defined in Equation (6). Measurements were repeated as many times as required to reach $2 \%$ relative standard deviation. 


$$
h=\frac{t_{c}}{t_{v} t_{s}}
$$

The $t_{c}$ is the time (s) for the glycerol to flow through calibration viscometer with diameter of $0.58 \pm 0.02 \mathrm{~mm}, \mathrm{t}_{\mathrm{v}}$ is the time for glycerol to efflux through the capillar-tube viscometer that is used for the sample solutions, and, $\mathrm{t}_{\mathrm{s}}$ is the time for $0.5 \mathrm{M}$ CED solution to efflux through the calibration viscometer.

$$
\eta_{\text {sample }}=\frac{T}{\rho}
$$

The $T$ is the tabulated empirical value for a given sample with efflux time $t$, and, $\rho$ is the mass concentration $\left(\mathrm{g} \cdot \mathrm{mL}^{-1}\right)$ of the sample.

$$
\eta_{\text {ratio }}=\frac{\eta}{\eta_{0}}=h \cdot t
$$

The $t$ is the time $(s)$ for the test solution to pass through the capillary viscometer.

\subsubsection{Adsorption Isotherms}

An adsorption isotherm with $\mathrm{MB}$ was conducted at $298 \mathrm{~K}\left(25^{\circ} \mathrm{C}\right)$ as described by Fardim et al. [32]. Fibers with oven dry mass of $102 \pm 2 \mathrm{mg}$ were suspended in $3 \mathrm{~mL}$ of deionized water for $30 \mathrm{~min}$. Methylene blue solution ( $\mathrm{c}=400 \mu \mathrm{M}$ ) was then added into the sludge and the sorption was allowed to proceed at $298 \mathrm{~K}\left(25{ }^{\circ} \mathrm{C}\right)$ for 15 min under gentle shaking. The MB solution was buffered with $600 \mu \mathrm{M}$ barbital to $\mathrm{pH}$ 8.2. Samples were filtrated through a glass fiber filter under reduced pressure after the sorption process. Filtrate was diluted 20 fold in $20 \mathrm{~mL}$ volumetric flask. The method was also applied with MY adsorption experiments. Approximately $30 \mathrm{mg}$ of pulp fibers were allowed to soak and react with the adsorbate as in MB sorption experiment. Initial concentration of MY solution was $49 \pm 1 \mu \mathrm{M}$. The adsorption isotherms were constructed by using different volumes of adsorbate solution. Ionic strength was controlled with $\mathrm{KCl}$ and set to $1 \mathrm{mM}$. Concentration of an equilibrium filtrate was recorded with UV-Vis instrument. Wavelength maxima for MB was $664 \mathrm{~nm}$ and $436 \mathrm{~nm}$ for MY.

Adsorption isotherms were evaluated with the Langmuir model defined in Equation (7), where $[i]_{e q}$ is the equilibrium concentration of the adsorbate and $K$ is the equilibrium constant. Noting that the surface coverage $(\theta)$ can be expressed as a fraction of adsorbed substances at equilibrium $\left(a_{e q}\right)$ to maximum adsorption $(n)$, the equation can be rearranged according to Equation (8). The correlation factor of fitted straight line for each sample was greater than $99 \%$.

$$
\begin{gathered}
\theta=\frac{K \cdot[i]_{e q}}{1+K \cdot[i]_{e q}} \\
\frac{a_{e q}}{n}=\frac{K \cdot[i]_{e q}}{1+K \cdot[i]_{e q}} \Leftrightarrow \frac{[i]_{e q}}{a_{e q}}=\frac{1}{n K}+\frac{[i]_{e q}}{n}
\end{gathered}
$$




\section{Results and Discussion}

\subsection{LDH Synthesis}

\subsubsection{X-Ray Diffractometry}

The XRD difraction patterns for neat LDH and for a commercial reference (HT) are shown in Figure 2 and the data is tabulated in Table 1. For each lattice diffractions the full width half maximum (FWHM) values and basal spacing $(l)$ increased in the order of LDH-U $<$ LDH-C $<\mathrm{HT}<\mathrm{LDH}-\mathrm{OH}$. Particle size should follow the reverse order. Asymmetric line broadening of 012 and 015 reflections in LDH-OH was also noticed with highest calculated basal spacing $l$. One possibility is that LDH-OH is a randomly intergrown rhombohedral structure as described by Evans and Slade [33]. Interstatification of hydroxyl ions has most likely occured, but also, $\mathrm{NO}_{3}^{-}$may have entered into the gallery due to statistical reasons because metal nitrates were used in synthesis. Experimental results may also arise from micro strain induced lattice distortions and from the inclusion of water molecules [33]. In any case, the LDH structures can be assigned as one layer polytypes.

Table 1. The characteristic diffraction angles $(2 \theta)$, fitted lattice parameters $(a=b, c)$ assuming R-3m space group symmetry, basal spacing $(l)$, full width half maximum values (FWHM), relative peak hight (RPH) and signal to noise ratio $(\mathrm{S} / \mathrm{N})$ are presented for each LDH sample. The generally known Miller indices $(h k l)$ for each recorded lattice spacings in $\mathrm{LDH}$, that are stacked in rhombohedral sequence via octahedral arrangement of $\mathrm{OH}$ groups, are: 003, 006, 012 and 015 .

\begin{tabular}{cccccccc}
\hline \multirow{2}{*}{ Sample } & $\mathbf{2 \theta}$ & $\boldsymbol{a}=\boldsymbol{b}$ & $\boldsymbol{c}$ & $\boldsymbol{l}$ & $\mathbf{F W H M}$ & $\mathbf{R P H}$ & \\
\cline { 2 - 7 } & $\mathbf{d e g}$. & $\AA$ & $\AA$ & $\AA$ & deg. & $\boldsymbol{\%}$ & S/N \\
\hline \multirow{4}{*}{ HT } & 11.68 & 3.10 & 22.73 & 7.58 & 0.522 & 100 & 360 \\
& 23.28 & & & & 0.781 & 29 & 105 \\
& 34.90 & & & & 0.763 & 14 & 50 \\
& 39.44 & & & & 0.613 & 14 & 50 \\
\hline \multirow{4}{*}{ LDH-U } & 11.85 & 3.04 & 22.45 & 7.48 & 0.266 & 100 & 280 \\
& 23.71 & & & & 0.309 & 33 & 93 \\
& 35.04 & & & & 0.257 & 11 & 31 \\
& 39.70 & & & & 0.297 & 11 & 30 \\
\hline \multirow{4}{*}{ LDH-C } & 11.75 & 3.08 & 22.61 & 7.54 & 0.459 & 100 & 47 \\
& 23.53 & & & & 0.426 & 55 & 26 \\
& 34.60 & & & & 1.000 & 32 & 15 \\
& 39.52 & & & & 0.631 & 21 & 10 \\
\hline \multirow{3}{*}{ LDH-OH } & 11.71 & 3.09 & 22.77 & 7.59 & 0.893 & 100 & 37 \\
& 23.44 & & & & 1.125 & 43 & 16 \\
& 34.63 & & & & 1.302 & 35 & 13 \\
& 38.68 & & & & 1.830 & 14 & 5 \\
\hline
\end{tabular}




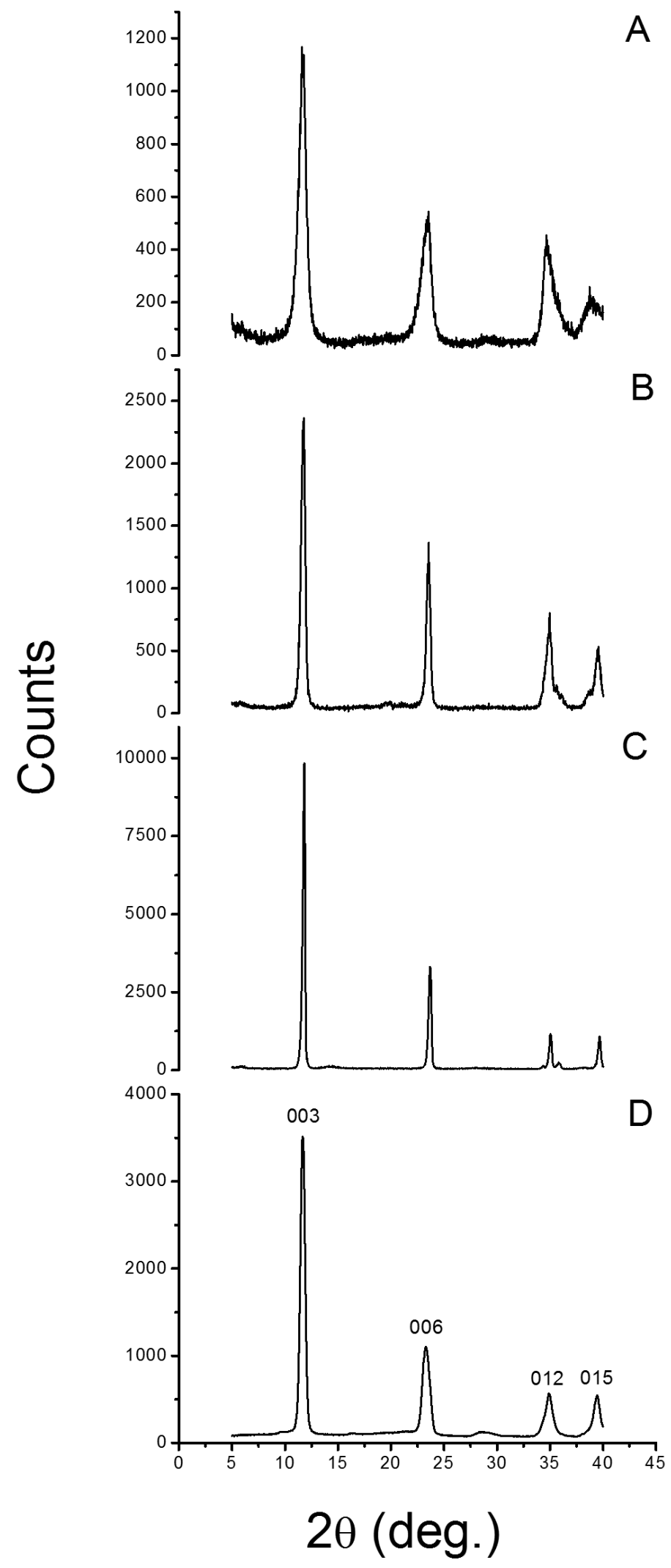

Figure 2. The XRD signals for different LDH particles are presented. (A) $\mathrm{LDH}-\mathrm{OH}$; (B) LDH-C; (C) LDH-U and (D) commercial HT . 


\subsubsection{Thermogravimetry}

The TG and differential thermal analysis (DTA) from the neat LDH particles are shown in Figure 3. Thermogravimetric response of a typical LDH can be divided into three sections [34] in the given temperature range where LDH structure can still be reconstructed in aqueous environment. First is the loss of adsorbed water and partial dehydroxylation until $\mathrm{T}=523 \mathrm{~K}\left(250^{\circ} \mathrm{C}\right)$. Depending on the LDH structure, some interlayer water may be lost already at this stage [35]. The accompanying loss of chemically bound water from the LDH galleries appears in between 548 and $623 \mathrm{~K}\left(275-350{ }^{\circ} \mathrm{C}\right)$. Some carbonates and hydroxyls are removed as well. It has been proposed that the dehydroxylation of $\mathrm{Al}-\mathrm{OH}$ takes place some $30 \mathrm{~K}$ before $\mathrm{Mg}-\mathrm{OH}$ that is accompanyed by decarbonation [35]. Crystal lattice reordering will, therefore, begin to take place in this temperature range. The third endotherm starting from around $650 \mathrm{~K}\left(377^{\circ} \mathrm{C}\right)$ is associated with significant loss of $\mathrm{CO}_{2}$ and $\mathrm{OH}$ during which the layered structure collapses and oxolation to $\mathrm{M}^{\mathrm{II}}-\mathrm{O}-\mathrm{M}^{\mathrm{III}}$ occurs.

The first endothermic signal in $\mathrm{LDH}-\mathrm{OH}$ is spread over a large temperature range until $505 \mathrm{~K}\left(232{ }^{\circ} \mathrm{C}\right)$ during which $15.2 \%$ from weight is lost (Figure 3A1,2). Most of the weight reduction comes from loss of water but some hydroxyls may be removed as well. Since the water is removed gradually from the LDH structure without a sharp endotherm except at the very end of the temperature range, an amorphous structure can be envisaged. The separation of the two main endothermic peaks was smallest in $\mathrm{LDH}-\mathrm{OH}$ sample $(\Delta \mathrm{T}=160 \mathrm{~K}$ ) leaving the endotherms at the middle temperature range, denoting loss of chemically bound water, carbonate and hydroxyl, almost invisible. A subtle shoulder in TG is found at $590 \mathrm{~K}\left(317^{\circ} \mathrm{C}\right)$. The remaining temperature range is characterized with $28.6 \%$ reduction in weight. The LDH-OH seem to loose majority of hydroxyls and carbonates in reactions where the separation in between dehydroxylation of $\mathrm{Al}-\mathrm{OH}$ and $\mathrm{Mg}-\mathrm{OH}$ and decarbonation processes can not be made.

For $\mathrm{LDH}-\mathrm{C}$ the first temperature range proceeds up to $513 \mathrm{~K}\left(240{ }^{\circ} \mathrm{C}\right)$ with $14 \%$ weight reduction (Figure 3B1,2). An exothermic signal at $555 \mathrm{~K}\left(282^{\circ} \mathrm{C}\right)$ was found in the second temperature range that is characterized by loss of chemically bound water, carbonates and hydroxyls from Al-OH. It is not clear from which phenomenon the exotherm originates exactly. Detected endothermic shoulder at around $595 \mathrm{~K}\left(322^{\circ} \mathrm{C}\right)$ may arise from dehydroxylation of $\mathrm{Mg}-\mathrm{OH}$ and loss of carbonate. Weight was reduced by $13.4 \%$. Concomitant loss of residual carbonate is denoted as a last endotherm at $673 \mathrm{~K}\left(400{ }^{\circ} \mathrm{C}\right)$ with $15.8 \%$ weight loss continuing until $873 \mathrm{~K}\left(600^{\circ} \mathrm{C}\right)$.

Thermogravimetry of $\mathrm{LDH}-\mathrm{U}$ has three distinctive endotherms in each temperature range already explained (Figure $3 \mathrm{C} 1,2)$. The endothermic signals are located at $468 \mathrm{~K}\left(195{ }^{\circ} \mathrm{C}\right), 558 \mathrm{~K}\left(285^{\circ} \mathrm{C}\right)$ and $698 \mathrm{~K}\left(425^{\circ} \mathrm{C}\right)$. Accompanying weight losses are $14.1 \%, 7.4 \%$ and $19.2 \%$ respectively. We propose that a loss of interlayer water and dehydroxylation of Al-OH occurs at $558 \mathrm{~K}\left(285^{\circ} \mathrm{C}\right)$ while dehydroxylation of $\mathrm{Mg}-\mathrm{OH}$ and loss of carbonates are simultaneous processes at $698 \mathrm{~K}\left(425^{\circ} \mathrm{C}\right)$.

It should be noted also, when comparing TG from $\mathrm{HT}$ and $\mathrm{LDH}-\mathrm{C}$, that competing reactions may take place in temperature range of $550-570 \mathrm{~K}\left(277-297^{\circ} \mathrm{C}\right)$. The reference particles seem to express a small endotherm at $564 \mathrm{~K}\left(291^{\circ} \mathrm{C}\right)$ while concomitant weight loss is $11.7 \%$ (Figure 3D). Also, the endothermic signal that is assigned for significant loss of $\mathrm{CO}_{2}$ and $\mathrm{OH}$ moves further to higher temperatures in the order $l s s<h s s<\mathrm{HT} \simeq$ Uhyd thus pointing towards thermodynamic stability of the carbonates in the 
LDH gallery. Furthermore, LDH-OH may have significant amount of interstratified $\mathrm{NO}_{3}^{-}$in its structure that lowers the apparent thermodynamic stability.

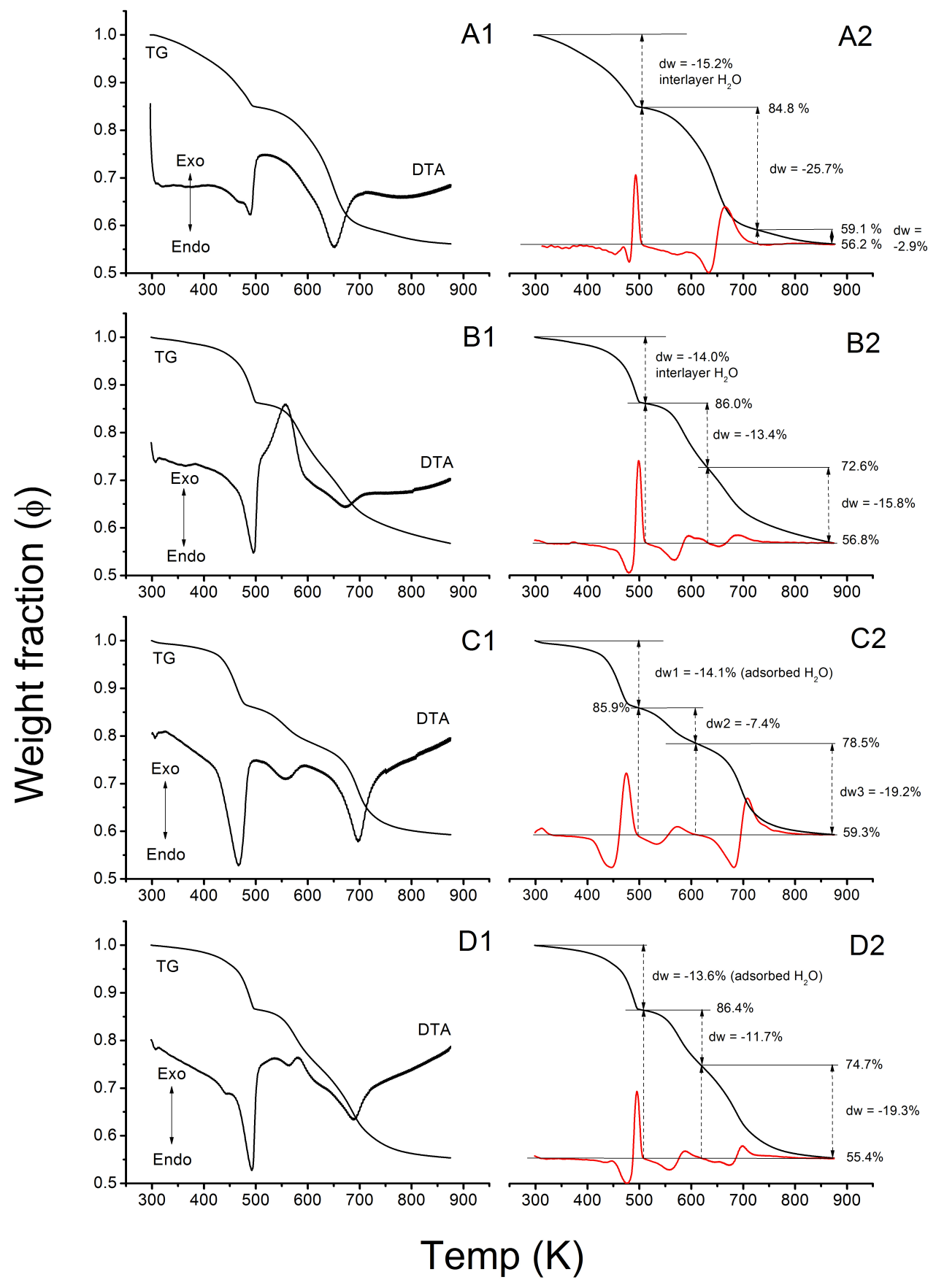

Figure 3. The weight fraction $(\phi)$ for LDH-OH (A); LDH-C (B) and LDH-U (C) particles is plotted as a function of temperature (T); Commercial HT (D) is shown as a reference. Endo- and exotherms are presented in (A1-D1). Rationale for weight reductions from experimental values are shown in (A2-D2). Second derivative of TG is shown in red. 


\subsubsection{ATR-FTIR}

The area of group frequencies above $2750 \mathrm{~cm}^{-1}$ shows similarities between HT, LDH-OH and LDH-C (Figure 4A). Two sharp peaks at 2917 and $2850 \mathrm{~cm}^{-1}$ vibration frequencies were found from HT, LDH-C and, albeit as extremely weak shoulders that are not resolved in the given figures, from LDH-OH. For LDH-U, a broad asymmetric signal was observed instead, but it may be that the sharp signals are embedded underneath. The shoulder at around $3000 \mathrm{~cm}^{-1}$ is attributed to hydrogen bond stretching between carbonate and water within the LDH gallery [36].
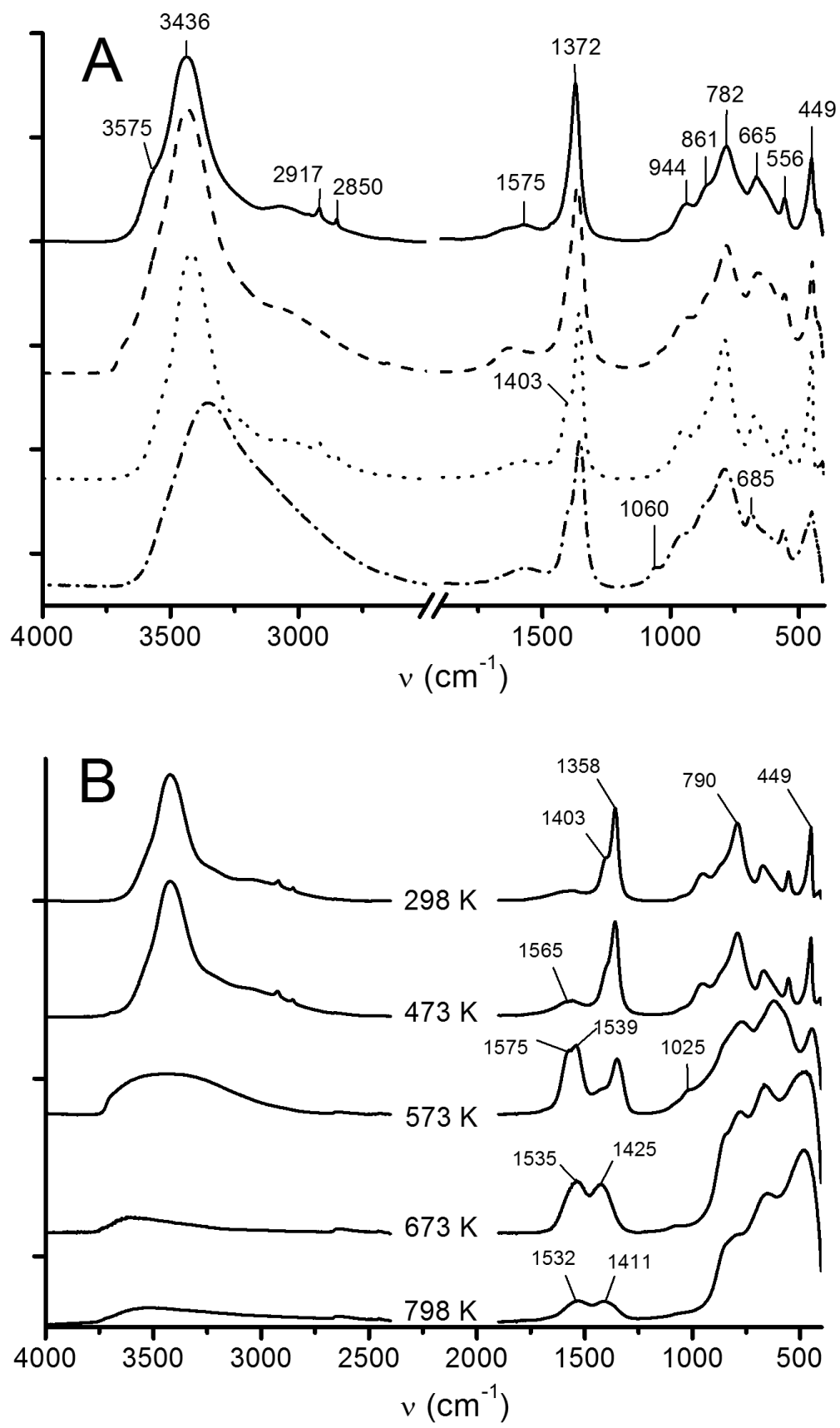

Figure 4. ATR-FTIR spectra of (A) different LDH particles with commercial reference (HT); and (B) after thermal decomposition of LDH-C particles. HT (-), LDH-OH (- - -), LDH-C $(\cdots)$ and LDH-U $(-\cdot-)$. 
The asymmetric stretching vibrations $\left(\nu_{3}\right)$ from $\mathrm{CO}_{3}^{2-}$ in the $\mathrm{LDH}$ gallery were observed at $1372-1358 \mathrm{~cm}^{-1}$ (Figure 4A). Out-of-plane bending vibration $\left(\nu_{2}\right)$ appears at about $860 \mathrm{~cm}^{-1}$ and in-plane bending $\left(\nu_{4}\right)$ at $665 \mathrm{~cm}^{-1}$. A shoulder in $\nu_{3}$ vibration at $1403 \mathrm{~cm}^{-1}$ was found in LDH-C and LDH-U samples. The symmetric stretching vibration $\left(\nu_{1}\right)$ of $\mathrm{CO}_{3}^{2-}$ at $1060 \mathrm{~cm}^{-1}$ is IR inactive in the free ion, but may become visible if the space symmetry is changed $[33,37]$. This symmetry change is often related to the splitting of $\nu_{3}$ into two, as planar $\mathrm{CO}_{3}^{2-} \mathrm{D}_{3 h}$ becomes pyramidal $\mathrm{C}_{2 v}$ or $\mathrm{C}_{s}[33,36,38]$. The split parameter of about $30-60 \mathrm{~cm}^{-1}$ in $\nu_{3}$ is proposed to arise due to a change in the force constant of hydrogen bonds between the $\mathrm{CO}_{3}^{2-}$ and $\mathrm{OH}$ groups in the interlayer lamina [33]. Differences in site and point symmetry-induced vibrational frequencies of carbonate in different minerals are well explained by Adler and Kerr [39]. The broad and small peak at around $1575 \mathrm{~cm}^{-1}$ arises from coordinated carbonate ions ([37], p. 284). Water may interfere at $1650 \mathrm{~cm}^{-1}$, at least in the $\mathrm{LDH}-\mathrm{OH}$ sample. It can be established then that in LDH-C and LDH-U, the carbonate occupies two different space symmetries owing to the splitting of $\nu_{3}$, while all samples have a broad peak at around $1575 \mathrm{~cm}^{-1}$, indicating both coordinated and free carbonate ions. It should be noted here, likewise, that the chosen precursors for LDH may obscure LDH-OH interpretation in that carbonate is replaced partially by nitrate ions. The vibrations for $\mathrm{NO}_{3}^{-}$are close to $\mathrm{CO}_{3}^{2-}$, so that differentiation is difficult.

The FTIR signals show typical changes upon thermal treatment of $\mathrm{LDH}$, as described, for example, by Ray et al. [40] (Figure 4B). First of all, the LDH-C is stable up to $473 \mathrm{~K}\left(200{ }^{\circ} \mathrm{C}\right)$. Splitting of the $\nu_{3}$ vibration of coordinated carbonate into two new bands $\left(1539 \mathrm{~cm}^{-1}\right.$ and $\left.1575 \mathrm{~cm}^{-1}\right)$ is detected at $573 \mathrm{~K}\left(300{ }^{\circ} \mathrm{C}\right)$. The relative intensity of $\nu_{3}$ at $1358 \mathrm{~cm}^{-1}$ is decreasing at the same time, while the splitting remains. The difference for $\nu_{3}$ in coordinated and free ions is $170-175 \mathrm{~cm}^{-1}$, depending on the synthesis route. Therefore, as water and hydroxyl ions are being lost from the LDH structure, the carbonate becomes coordinated and restricted by the symmetry at the same time. The stretch vibrations from coordinated $\mathrm{CO}_{3}^{2-}$ should appear also around $800-700 \mathrm{~cm}^{-1}$, but this area coincides with M-O stretch and $\mathrm{OH}$ deformation vibrations, and thus, cannot be used in detection. It should be noted here that owing to the basic principles of vibration spectra, the so-called polarization power of the cations in $\mathrm{LDH}$ must influence the hydrogen bonding strength of the associated $\mathrm{OH}^{-}$in octahedral sites that, in turn, will determine the difference in observed vibrational spectra between the coordinated carbonate and the free ion. Carbonate that is coordinated as a bidentate ligand should have greater separation of the vibrational adsorption band to the free ion than a monodentate ligand has. Therefore, the carbonate in each synthesized LDH particle occupies a more or less similar site symmetry, either in uni-, or bi-dentate, or both, but we expect the carbonate to be a bidentate bridging ligand at $573 \mathrm{~K}\left(300{ }^{\circ} \mathrm{C}\right)$.

The area below $950 \mathrm{~cm}^{-1}$ changes significantly from $473-573 \mathrm{~K}\left(200-300{ }^{\circ} \mathrm{C}\right)$ and again from 573-673 K (300-400 $\left.{ }^{\circ} \mathrm{C}\right)$. The second and third endotherms detected in TG are located in these regions. Group vibrations for $\mathrm{OH}$ were also changing. The phenomenon is interpreted as a collapse of a layered structure due to loss of carbonate and the formation of mixed metal $\mathrm{M}^{\mathrm{II}}-\mathrm{O}-\mathrm{M}^{\mathrm{III}}$ bridges upon dehydroxylation [40]. The asymmetric $\nu_{3}$ vibrations from $\mathrm{CO}_{3}^{2-}$ changes, so that the splitting disappears and the difference between coordinated and free ion reduces to $100-120 \mathrm{~cm}^{-1}$ ). The carbonate signal represent more free-like ion and possibly monodentate coordination at $673 \mathrm{~K}\left(400{ }^{\circ} \mathrm{C}\right)$. The reduction in the bonding strength of carbonate to $\mathrm{M}^{\mathrm{I} / \mathrm{III}}-\mathrm{O}$ with a more free ion character is also expected. It is important to note that in the spectrogram of LDH-OH particles, a shoulder appeared at $1355 \mathrm{~cm}^{-1}$ after 
heating the sample up to $673 \mathrm{~K}\left(400{ }^{\circ} \mathrm{C}\right.$ ) (see supporting Figure S1). This vibration fits rather well for the free $\mathrm{NO}_{3}^{-}$ion ([37], p. 285).

\subsection{Mineralization and Coating of Pulp Fibers}

The reference pulp that was used in all experiments was fully bleached Kraft fibers from pine. The Kappa number of such pulps is usually less than 4 even after moderate bleaching stages, and, it is affected by residual lignin, hexenuronic acids as well as other carbohydrates that contain $\mathrm{sp}^{2}$ hybridized carbons with double bonds ([41], p. 769). The residual lignin content in delignified and bleached softwood fibers after Kraft process is very low and average cellulose and hemicelluloses content are in the range of $85 \%$ and $15 \%$ respectively ([41], p. 1013).

\subsubsection{Microscopy}

SEM images (Figure 5A1-C1) confirmed that the hydrolytically synthesised particles with pulp fibers appeared similar to typical LDH that has been synthesised by other authors in absence of template structures such as fibres $[26,42,43]$. The hexagonal shape was especially clear from clay sized particles (insets in Figure 5C1,2). All synthesis routes produced uniformly distributed particles on fibers external surfaces. Also, the particles size followed the proposed order from XRD. The LDH from lss and hss solutions were $\leq 200 \mathrm{~nm}$ while those from Uhyd were approximately $2-5 \mu \mathrm{m}$ in diameter. The SEM images taken after TG analysis indicated that the fibers were acting as templates for LDH (Figure 5A2,B2 and C2).

Surprisingly, effective particle nucleation within the $\mathrm{S} 2$ cell wall was discovered with TEM after Uhyd synthesis (Figure 6A). We concluded that the LDH particles were not spread over the imaged area by the diamond blade during ultra-thin sectioning of epoxy moulded specimen as there were no similarly distributed particles to be seen anywhere over the polymer matrix apart from some agglomerated bundles that were found in ultra thin sections from hss and lss treated fibers (Figure 6B,C). We expect that the particle nucleation within the fiber wall was inhibited in hss system due to rapid $\mathrm{pH}$ change that signify rapid olation of ions prior to crystall growth. In lss route, on the other hand, the fibres were completely saturated and swollen as the $\mathrm{pH}$ was kept above 9 throughout the reaction. The nucleation kinetics prevented, however, the diffusion of $\mathrm{Mg}^{2+}$ and $\mathrm{Al}^{3+}$ ions into the cell wall structure albeit in some TEM images small amount of nanoparticles were observed in S2 layer. Colloidal particles can therefore migrate into the fiber wall to some extent. Swelling and nucleation in Uhyd system was expected to be slow and fully controlled by the rate of urea hydrolysis. 

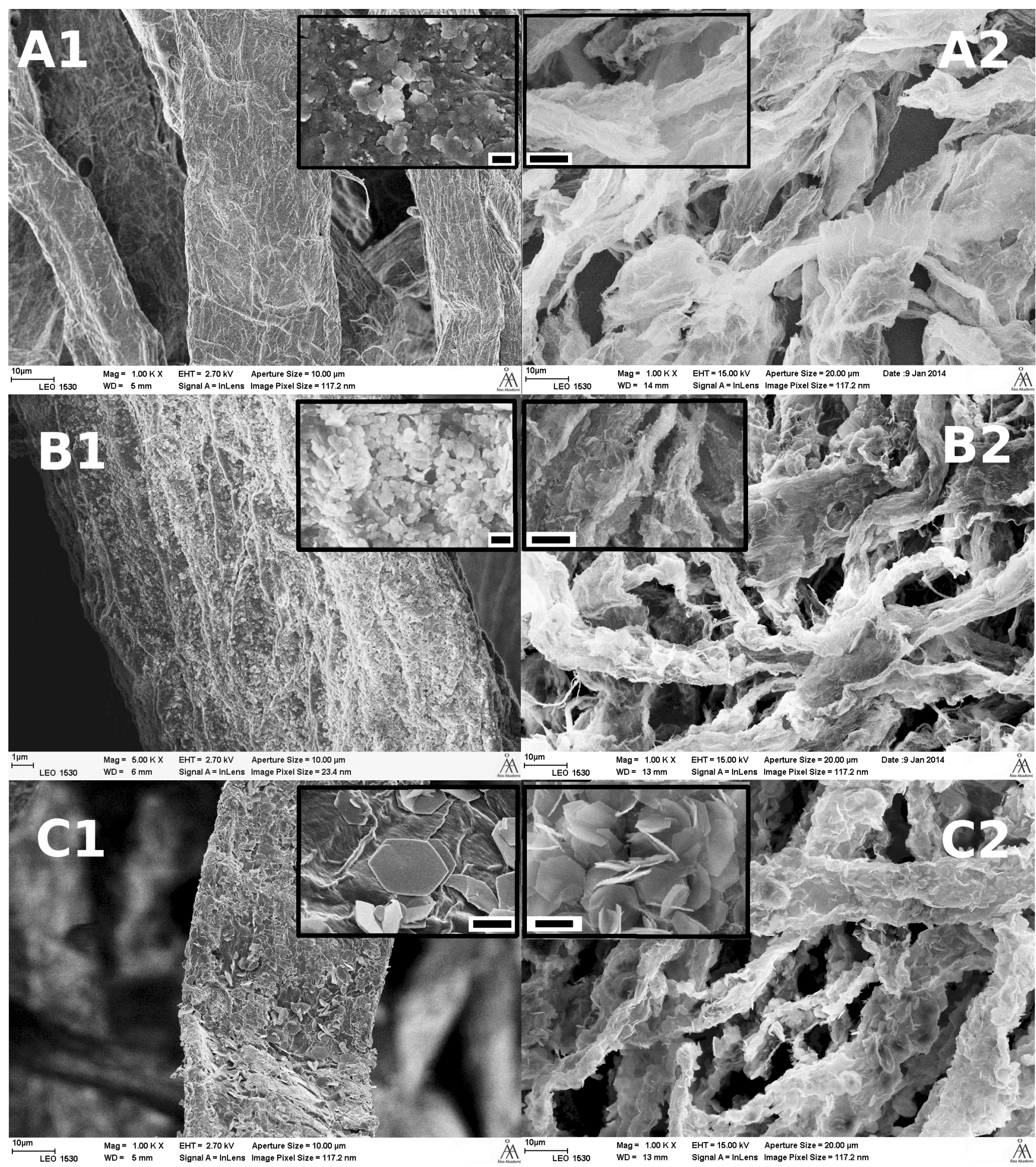

Figure 5. SEM images of (A) lss synthesised; (B) hss synthesised and (C) Uhyd synthesised fibers before (1) and after (2) TG analysis. The scale bar in the insets are (A1 and B1) $200 \mathrm{~nm}$ and $(\mathbf{C} 1-\mathbf{C} 2) 2.0 \mu \mathrm{m}$. The width of a collapsed wood fiber before incineration was approximately $30-40 \mu \mathrm{m}$. 


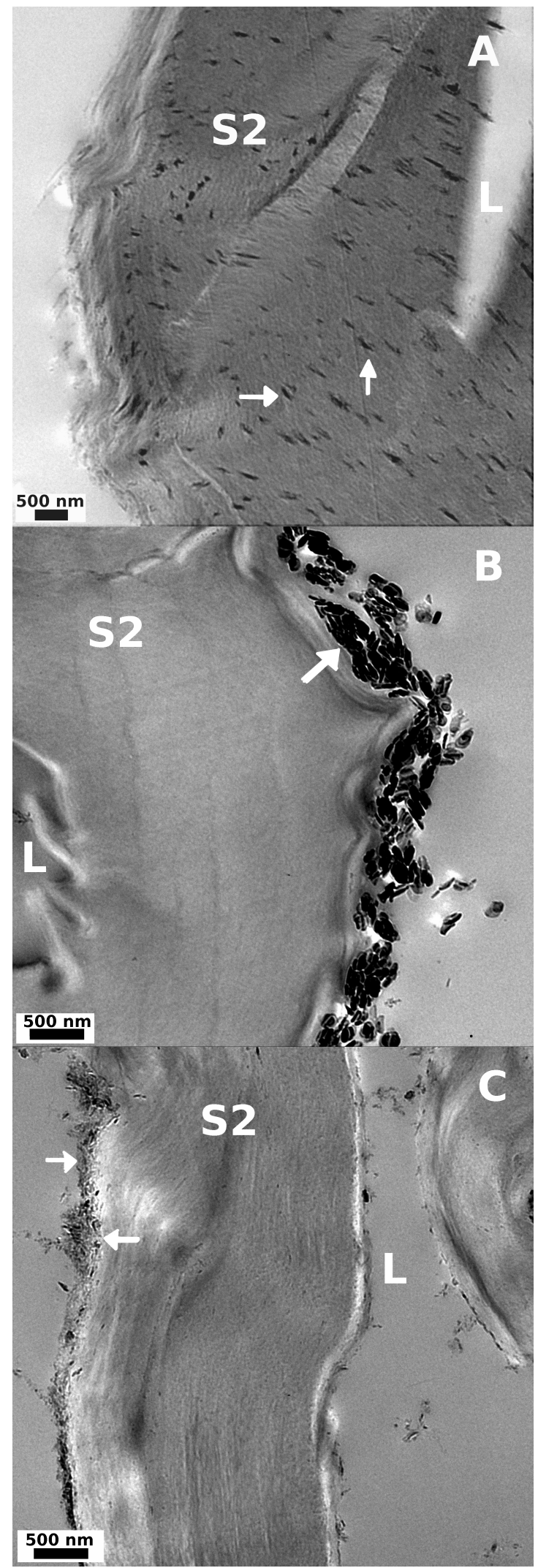

Figure 6. TEM images from transverse cut (A) Uhyd and (B) hss; and (C) longitudinal cut $l s s$ treated fibers. The particle size follows the order LDH-U $>$ LDH-C $>$ LDH-OH. Fiber lumen (L) and cell wall (S2) are visible in all samples. LDH is marked with arrows. 
The reason for the patterned and apparently lamellar distribution of nanoparticles in S2 cell wall after Uhyd synthesis is unknown, but, we assume that the existence of carboxyl functionalities in a form of hexenuronic and 4-O-glucuronic acids plays an important role (c.f. Section 3.2.6). Pore size will undoubtedly affect to migration of nano-particles and nucleation within the cell wall structure as well. Depending on the chosen pulping technique the pore size distribution can extend to meso and macro range up to $30 \mathrm{~nm}[44,45]$. There is also evidence that the swollen fibres have even larger pores up to $100 \mathrm{~nm}$ in size [46]. The pore size and depth in fibers transverse direction was not addressed. It is also known that fiber swelling is somewhat reduced in a solvent with high ionic strength [47]. Considering the differences in between the hss and Uhyd synthesis routes, the electrostatic driven diffusion of $\mathrm{Mg}^{2+}$ and $\mathrm{Al}^{3+}$ ions into fiber wall must be rapid and occur at elevated $\mathrm{pH}$ preceding particle formation. The rationale goes as follows. First of all, in hss system the fiber swelling lacks behind $\mathrm{pH}$ change whereas in Uhyd the extent of swelling and $\mathrm{pH}$ increase are approximately concomittant processes. In alkaline environment the fiber swelling gradually advances with the aid of increased temperature. Increasing the activity of hydroxyls will draw cations into the fiber wall [48]. Increase in ionic strength within the cell wall will ultimately cause the swelling as water enters into the structure due to osmotic pressure that, at some $\mathrm{pH}$, will overcome the cohesion of the lamellar structure in radial direction of the fibre and change its structure $[45,49]$ allowing more of the bound charged groups to be available for cations to interact. It is known that the $\mathrm{pK}_{a}$ for uronic acid in pulp is approximately 3.1-3.3 [50]. The $\mathrm{pH}$ for a solution in which the pulp fibers were soaked prior to hydrothermal treatment containing $\mathrm{Mg}^{2+}$ and $\mathrm{Al}^{3+}$ ions was 3.7 at which, considering the $\mathrm{pK}_{a}$, some $60 \%-75 \%$ of uronic acids are deprotonated. The interaction and distribution of different metal ions with apparent equilibrium constants in between pulp fibres and bulk solution at diffirent $\mathrm{pH}$ have been addressed by many authors [51-53]. It is therefore possible that the water molecules in the S2 cell wall are partially exchanged to urea, and, at the hydrolysis temperature, ammonia and carbonate induce local $\mathrm{pH}$ increase within the fiber wall facilitating the diffusion of ions into the fiber structure according to Donnan equilibrium model, and, ultimatly leading to formation of $\mathrm{Mg}(\mathrm{OH})_{2}$ and $\mathrm{Al}(\mathrm{OH})_{3}$ and $\mathrm{LDH}$. The validitiy of Donnan model in context of pulp fibers is discussed in several papers [54-56]. The consensus is that Donnan model is satisfactory at moderate $\mathrm{pH}$ range (3-6) where precipitation of metal hydroxides do not occur and ion interactions with semi-permeable membrane, i.e., fibre cell wall, are non-specific [57-59].

We cannot rule out at this point the possibility that the nucleation within the $\mathrm{S} 2$ cell wall produces other than LDH particles also. It is evident from TEM and SEM images, however, that all synthesis routes coagulate LDH particles effectively onto the fiber surface. Particle size from $h s s$ system is observed to be close to the one found in SEM images. The lss synthesis route produced particles with size in the nano regime $(<100 \mathrm{~nm})$. Significant densification of pulp fibers was expected because of the mineralization action of Uhyd treatment (c.f. Section 3.2.5).

\subsubsection{Thermogravimetry}

Changes in weight were recorded after thermal stabilization at $473 \mathrm{~K}\left(200{ }^{\circ} \mathrm{C}\right)$ (c.f. Section 2.2.4). The point where the rate of mass change exceeded $-0.025 \mathrm{mg} \cdot \mathrm{K}^{-1}$ was chosen as the onset temperature (Figure 7A inset). Onset temperature for the reference pulp was $497 \pm 3 \mathrm{~K}\left(224 \pm 3{ }^{\circ} \mathrm{C}\right)$ while the LDH modified pulp samples showed insulating effect up to $519 \mathrm{~K}\left(246{ }^{\circ} \mathrm{C}\right)$. Regardless of the onset 
temperature, the first combustion reaction levelled out in each sample at $620 \mathrm{~K}\left(347^{\circ} \mathrm{C}\right)$. The mass loss rate appeared higher for lss and Uhyd samples (Figure 7A).
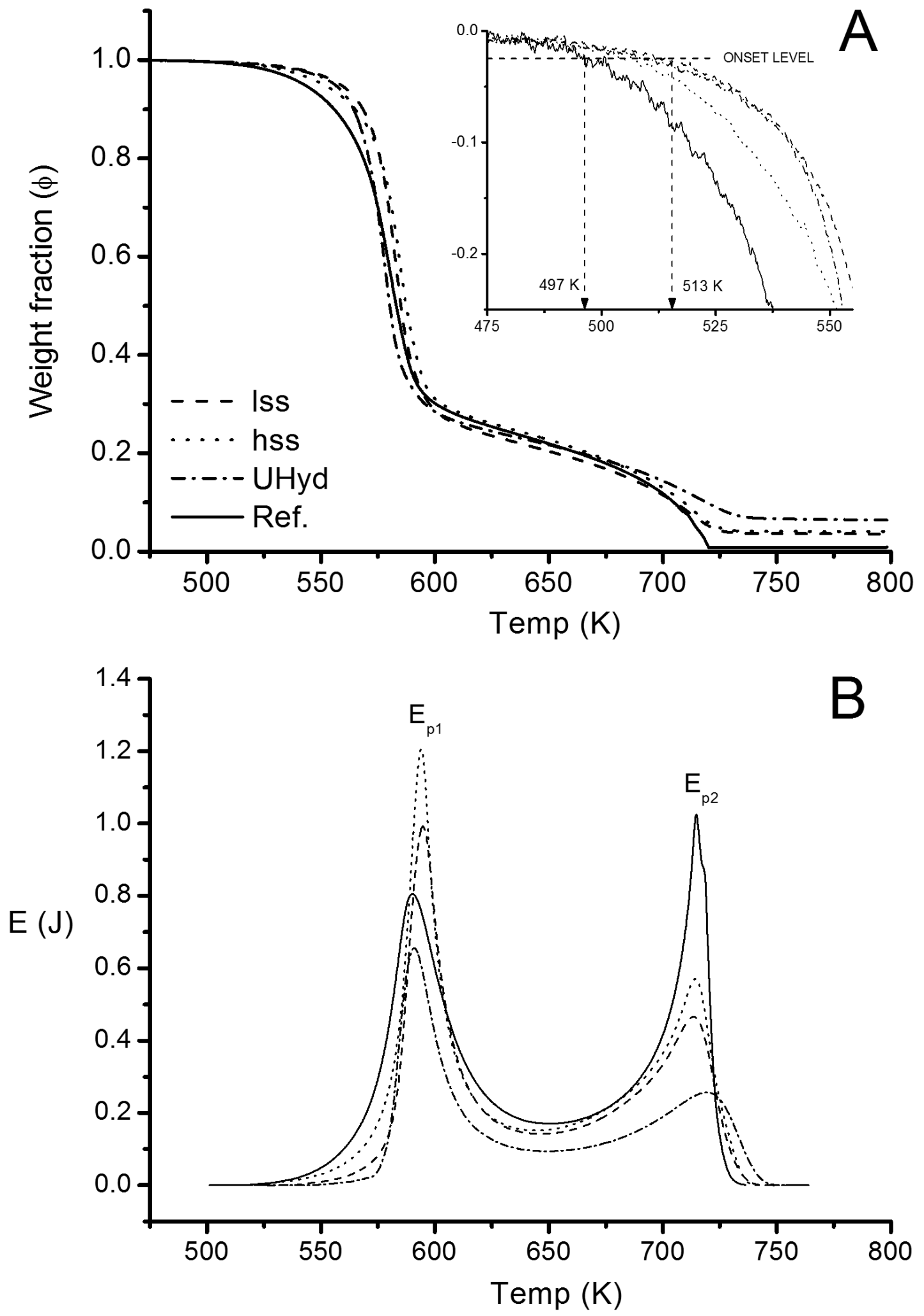

Figure 7. (A) The thermograms and onset temperature analysis (inset) for oxidative combustion of fully bleached Kraft pulp fibres from Pine with LDH (lss, hss, Uhyd) and without (Reference) (A); and released energy at a given temperature $(\mathbf{B})$ are presented. 
Pulp fiber degradation occurred in two phases with the chosen set up. First mass loss at around 498-620 K (225-347 $\left.{ }^{\circ} \mathrm{C}\right)$ comprised approximately $77 \%$ from the dry weight and produces oxidised cellulose and carbon containing char. Second mass loss occurred at 673-748 K (400-475 $\left.{ }^{\circ} \mathrm{C}\right)$. Combustion is characterized with $\mathrm{CO}_{2}, \mathrm{CO}$ and $\mathrm{CH}_{4}$ evolution from hemicelluloses and cellulose [60]. The main gaseous component, $\mathrm{CO}_{2}$, is released in two phases. For hemicellulose (xylan) the release occurs at 518 and $623 \mathrm{~K}\left(245{ }^{\circ} \mathrm{C}\right.$ and $350{ }^{\circ} \mathrm{C}$ ) while for cellulose (micro crystalline) the peaks are at 593 and $748 \mathrm{~K}\left(320^{\circ} \mathrm{C}\right.$ and $\left.475{ }^{\circ} \mathrm{C}\right)$ [61]. The results were obtained under airflow.

The average residual mass from hss, lss and Uhyd pulps were $3.6 \%, 4.1 \%$ and $6.5 \%$ respectively (Figure 7A). Standard deviation for the residual mass in each pulp was 2\%. The standard deviation increased with the amount of LDH in pulp, probably due to small sample weight that was required for TG experiments. Fully bleached Kraft reference pulp fibers contained approximately $0.8 \% \pm 0.2 \%$ of ash. Using the weight loss data from TG analysis of pristine LDH particles (Figure 3) it is possible to calculate the initial weight fraction of $\mathrm{LDH}\left(\Psi_{L D H}^{\circ}\right)$ for each pulp samples. The values are given in Table 2. The apparent relative weight increase of organic substances $\left(\Psi_{\text {org }}^{473}\right)$ was due to chosen reference point at $473 \mathrm{~K}\left(200{ }^{\circ} \mathrm{C}\right)$. LDH had lost approximately $14 \%-15 \%$ in a form of water (Figure 3 ) at that temperature. The standard deviation of detected weight fraction after the first exotherm was approximately $2.5 \%$ regardless of the sample. Hence, the fraction $(\Delta \Psi)$ was averaged over the entire sample set.

Table 2. The calculated weight fraction of organic material (org) and LDH particles in LDH containing fibers are presented at three different temperatures: initial stage at $298 \mathrm{~K}\left(25^{\circ} \mathrm{C}\right)$ ( $\Psi_{\text {org }}^{\circ}$ and $\left.\Psi_{L D H}^{\circ}\right)$, after conditioning at $473 \mathrm{~K}\left(200{ }^{\circ} \mathrm{C}\right)\left(\Psi_{\text {org }}^{473}\right.$ and $\left.\Psi_{L D H}^{473}\right)$ and prior to the second exotherm at $643 \mathrm{~K}\left(370{ }^{\circ} \mathrm{C}\right)\left(\Psi_{\text {org }}^{643}\right.$ and $\left.\Psi_{L D H}^{643}\right)$. Relative average total mass loss of material during the first exotherm $(\Delta \Psi)$ and relative total mass loss of LDH in combustion $\left(\Delta \Psi_{L D H}\right)$ are presented as well. Material specific unit energies for both corresponding exotherms $\left(\mathrm{E}_{\mathrm{p} 1}\right.$ and $\mathrm{E}_{\mathrm{p} 2} c f$. Figure $\left.7 \mathrm{~B}\right)$ with the total exothermic energy $\Sigma \mathrm{E}$ and the LDH reduced energy $\mathrm{E}_{\mathrm{p} 1}^{0}$ are included in the table.

\begin{tabular}{|c|c|c|c|c|c|c|c|c|c|c|c|c|}
\hline \multirow[t]{2}{*}{ Sample } & $\underline{\Psi}_{\text {org }}^{\circ}$ & $\Psi_{L D H}^{\circ}$ & $\Psi_{\text {org }}^{473}$ & $\Psi_{L D H}^{473}$ & $\Psi_{\text {org }}^{643}$ & $\Psi_{L D H}^{643}$ & $\Delta \Psi$ & $\Delta \Psi_{L D H}$ & $\mathbf{E}_{\mathrm{P} 1}$ & $\mathbf{E}_{\mathrm{P} 1}^{0}$ & $\mathbf{E}_{\mathrm{P} 2}$ & $\Sigma \mathbf{E}$ \\
\hline & \multicolumn{8}{|c|}{$\%$} & \multicolumn{4}{|c|}{$\mathbf{k J} \cdot \mathbf{g}^{-1}$} \\
\hline Reference & 100 & - & 100 & - & 100 & - & 78 & - & 3.9 & 3.9 & 11.7 & 15.6 \\
\hline lss & 95.0 & 5.0 & 95.8 & 4.2 & 84.5 & 15.5 & 78 & 43.8 & 2.6 & 3.1 & 7.3 & 9.9 \\
\hline hss & 94.2 & 5.8 & 95.0 & 5.0 & 81.8 & 18.2 & 78 & 43.4 & 3.0 & 3.7 & 7.6 & 10.6 \\
\hline Uhyd & 90.4 & 9.7 & 91.7 & 8.3 & 67.0 & 33.0 & 78 & 40.8 & 1.7 & 2.5 & 4.3 & 5.0 \\
\hline
\end{tabular}

In order to relate the exothermic signals from DTA to the combustion enthalpies $\left(\Delta_{c} U\right)$, the instrument was calibrated with high purity $\mathrm{Pb}$ and $\mathrm{Zn}$ standards. Fusion enthalpies were chosen from a critical review by Stølen and Grønvold [62]. Corresponding experimental properties are given in Table 3. Since the thermogravimetric data for modified pulp samples spans over a range of 520-740 K $\left(247-467{ }^{\circ} \mathrm{C}\right)$, the calculated unit energies from the standards were fitted with a linear function. The parameters for the linear fit $(y=a+b x)$ were: $a=0.039 \mathrm{~J} \cdot \mathrm{K}^{-2}$ and $b=3.8 \cdot 10^{-4} \mathrm{~J} \cdot \mathrm{K}^{-3}$. Exotherms from modified pulp fibers are shown in Figure 7B. The onset temperature for exothermic signals were determined from the first derivative of DTA curve. It should be noted that the recorded 
exo- and endotherms are influenced by the temperature ramp, carrier gas and its flow rate, initial material weight and its density, and, instrument design to some extent. Accurate enthalpies are therefore difficult to calculate in such open system. However, the calculated combustion enthalpy $(\Sigma E)$ for the reference fibers was reasonably close to the ones found in the literature $[63,64]$. The $\Sigma E$ was clearly reduced by the LDH especially after Uhyd synthesis (Table 2). Cellulosic polymers were expected to interact with LDH at the particle-polymer interphase. The calculated enthalpies related to the exotherm $\mathrm{E}_{\mathrm{p} 1}$ (Figure 7B and Table 2) suggests, at first, that LDH influence is size dependent and also affected by the location of the particles. For example, hss has higher $\mathrm{E}_{\mathrm{p} 1}$ than lss. However, when $\mathrm{E}_{\mathrm{p} 1}$ is corrected by removing the effect of $\mathrm{LDH}\left(\mathrm{E}_{\mathrm{p} 1}^{0}\right)$ a perfect correlation $(\mathrm{R} \simeq 1)$ in between the enthalpy and weight corrected intrinsic viscosity of the LDH containing fibers is found (c.f. Table 4). The paramters for a linear function $(y=a+b x)$ were: $a=526.5 \mathrm{~mL} \cdot \mathrm{g}^{-1}$ and $b=95.0 \cdot 10^{-3} \mathrm{~mL} \cdot \mathrm{J}^{-1}$. Furthermore the diffence in $\mathrm{E}_{\mathrm{p} 1}$ and $\mathrm{E}_{\mathrm{p} 1}^{0}$ provide means for evaluating the effect of $\mathrm{LDH}$. Enthalpy reduction in each case was substantial but the difference only from 0.5 to $0.8 \mathrm{~kJ} \mathrm{~g}^{-1}$ corresponding to $17 \%-25 \%$ reduction from the expected $3.9 \mathrm{~kJ} \cdot \mathrm{g}^{-1}$. increasing in order $l s s<$ hss $<$ Uhyd. Second exotherm $\left(\mathrm{E}_{\mathrm{p} 2}\right)$ correlated reasonably well with the residual $L D H$ content $\left(\Psi_{L D H}^{643}\right)$.

Table 3. The calibration standards with corresponding physical properties and experimental unit energies $\left(\Delta_{c} \mathrm{U}_{\text {unit }}\right)$ are presented. The $\Delta_{f u s} \mathrm{H}_{m}$ was acquired from Stølen and Grønvold [62] and the litterature values for the melting point onset (mp.) from Ditmars $(\mathrm{Zn})$ and Zahra \& Zahra $(\mathrm{Pb})[65,66]$.

\begin{tabular}{ccccccc}
\hline \multirow{2}{*}{ Standard } & $\mathbf{M}$ & $\boldsymbol{\Delta}_{\boldsymbol{f} \boldsymbol{u s}} \mathrm{H}_{\boldsymbol{m}}$ & $\mathbf{m p .}$ (Litterature Value) & $\mathbf{n}$ & $\mathbf{E}_{\boldsymbol{t o t}}$ & $\boldsymbol{\Delta}_{\boldsymbol{c}} \mathrm{U}_{\text {unit }}$ \\
\cline { 2 - 7 } & $\mathbf{g} \cdot \mathrm{mol}^{-\mathbf{1}}$ & $\mathbf{J} \cdot \mathrm{mol}^{-\mathbf{1}}$ & $\mathbf{K}$ & $\boldsymbol{\mu m o l}$ & $\boldsymbol{J}$ & $\mathbf{J} \cdot \mathrm{K}^{-\mathbf{2}}$ \\
\hline $\mathrm{Pb}$ & 207.20 & $4765 \pm 11$ & $600.13(600.61)$ & 243 & 1.158 & 0.2699 \\
$\mathrm{Zn}$ & 65.39 & $7103 \pm 31$ & $692.25(692.68)$ & 275 & 1.951 & 0.3054 \\
\hline
\end{tabular}

\subsubsection{ATR-FTIR}

The combustion induced spectral changes are depicted in Figure 8A-E. Isothermal conditioning at $473 \mathrm{~K}\left(200^{\circ} \mathrm{C}\right)$ removes all absorbed water from the pulp fibers. Fiber degradation was not observed at that temperature in the given timeframe. LDH is apparent only in $h s s$, due to thick particle layer on the fiber surface, as seen in TEM images, on this particular sample (Figure 8A). Material degradation occurred in each sample at $573 \mathrm{~K}\left(300{ }^{\circ} \mathrm{C}\right)$ as the $\mathrm{C}=\mathrm{O}$ stretching vibration appeared at $1726 \mathrm{~cm}^{-1}$ (Figure 8B). After initial combustion process at $613 \mathrm{~K}\left(340^{\circ} \mathrm{C}\right)$ the $\mathrm{LDH}$ containing fibers expressed various absorption vibrations from ketones and acids in the region of $1750-1400 \mathrm{~cm}^{-1}$. Some pyranose ring vibrations at $1400-1020 \mathrm{~cm}^{-1}$ were still visible in LDH containing samples. Approximately $70 \%$ of the material is lost at that temperature according to TG wherefore the characteristic $\mathrm{M}^{\mathrm{II}}-\mathrm{O}-\mathrm{M}^{\mathrm{III}}$ and M-O stretch vibrations from LDH becomes apparent below $900 \mathrm{~cm}^{-1}$ as well (Figure 8C). It should be noted that the $\nu_{3}$ vibrations from carbonate are located close to the carboxylic acid vibrations around $1600 \mathrm{~cm}^{-1}$ and $1410 \mathrm{~cm}^{-1}$. 

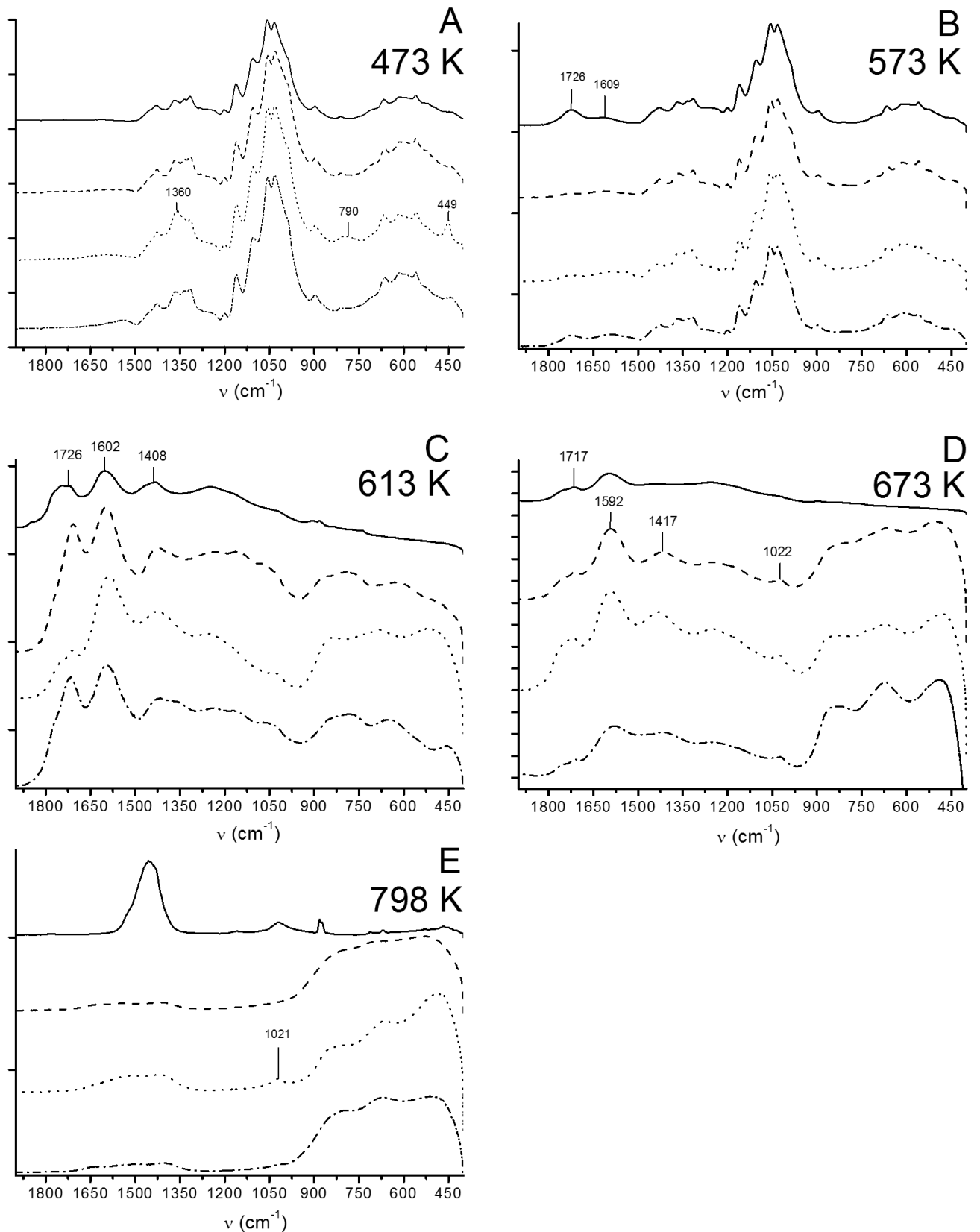

$\mathrm{E}$

Figure 8. ATR-FTIR spectra for thermal decomposition of fully bleached Kraft pulp reference (-), and, pulps with LDH (lss (- - ), hss ( - ) and Uhyd (- - -)).

A broad signal from charred products, mainly inorganic carbonates from $\mathrm{Na}, \mathrm{K}, \mathrm{Ca}$ and $\mathrm{Mg}$, after oxidation of cellulose at $798 \mathrm{~K}\left(525^{\circ} \mathrm{C}\right.$ ), appears to centre around $1450 \mathrm{~cm}^{-1}$ (Figure $8 \mathrm{E}$ ). The weak and broad signal at $1021-1022 \mathrm{~cm}^{-1}$ (Figure $8 \mathrm{D}, \mathrm{E}$ ) is assigned for metal oxides while the sharp and weak dublet in reference sample close to $900 \mathrm{~cm}^{-1}$ in figure $8 \mathrm{E}$ belongs, most likely, to metal carbonates as well. Stretch vibrations from $\mathrm{M}^{\mathrm{II}}-\mathrm{O}-\mathrm{M}^{\mathrm{III}}$ were present only in $\mathrm{LDH}$ containing samples.

Combustion kinetics was evalueted by treating the samples at $613 \mathrm{~K}\left(340{ }^{\circ} \mathrm{C}\right)$ for preset time intervals. The results are presented in Figure 9. Signal evolution proceeded gradually in all LDH containing samples (Figure 9A2-C2). Reference pulp fibers charred relatively slowly (Figure 9D2). However, after 
240 s the combustion kinetics increased markedly. All LDH modified samples contained organic material even after $420 \mathrm{~s}$ of combustion while reference pulp was practically incinerated.
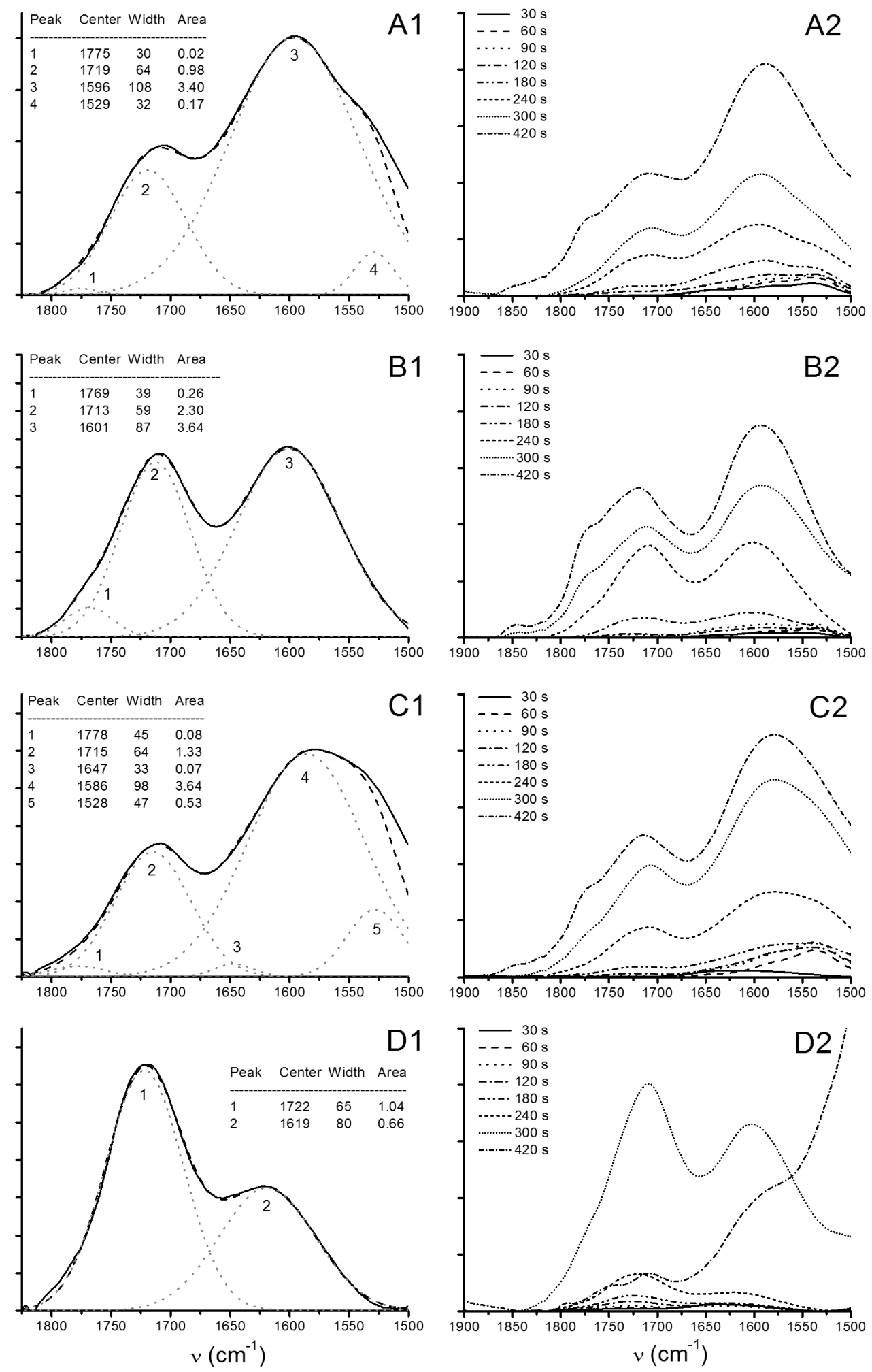

Figure 9. ATR-FTIR spectra from thermal decomposition kinetics of LDH containing pulps at $613 \mathrm{~K}\left(340{ }^{\circ} \mathrm{C}\right)((\mathbf{A}) l s s ;(\mathbf{B})$ hss; (C) Uhyd) and (D) fully bleached Kraft pulp reference. Deconvoluted FTIR spectra after $240 \mathrm{~s}$ in range of $1500-1850 \mathrm{~cm}^{-1}$ are presented in figures (A1-D1), and signal evolution within $420 \mathrm{~s}$ in figures (A2-D2). 
Deconvoluted spectra revealed the differences in combustion kinetics in each LDH containing samples (Figure 9A1-D1). The signal at around $1585-1620 \mathrm{~cm}^{-1}$ arises from diones, presumambly mainly from 1,3-diketones, while the absorption at around $1775-1720 \mathrm{~cm}^{-1}$ is assigned as carboxylic acids, aldehydes, and 1,2-diketones [37,67]. In all LDH containing samples but specifically in those that contained fiber wall penetrated particles (lss and $U h y d$ ) combustion produced partially oxidised cellulose in relatively high amounts. Pulp fibers without LDH were readily oxidised to carboxylic acids. We assume that the lower energy needed for aldehyde and dione formation drives the combustion in LDH containing samples due to loss of water and hydroxyls from LDH crystals. The carbonate in LDH particles contributed to the deconvoluted spectra of $l s s$ and Uhyh samples (peak numbered as 4 and 5 respectively). Similar effect with hss sample was observed after 300 s (Figure 9B2). Small contribution from water was also needed for the fitted curve in Uhyd to match the recorded absorption signals (peak number 3). The interference curve in lss and Uhyd deviates from the original below $1525 \mathrm{~cm}^{-1}$ due to additional signals originating from complex absorption of cellulose, and, carbonate in LDH gallery. Again we must make a note that in lss the contribution from nitrates should be bared in mind. We can not distinguish the fractional basis of $\mathrm{CO}_{3}^{2-}$ and $\mathrm{NO}_{3}^{-}$in peak number 4 (Figure 9A1).

\subsubsection{Capillary Viscometry}

To address the possible depolymerisation of cellulose, the intrinsic viscosity of fibers dissolved in cupriethylene diammine (CED) was measured with the capillary viscometer. Experimental values are listed Table 4. The weight corrected limiting viscosity numbers decreased in order of Reference $>$ hss $>l s s>$ Uhyd. Slow urea hydrolysis reduced the intrinsic viscosity approximately $20 \%$. It can be argued that neither the alkaline medium nor the existence or the amount of LDH was responsible for lowered viscosity number. The former argument is supported by the fact that the end $\mathrm{pH}$ was about $0.5-1.0$ units higher in hss system than in the other two. The possibility for LDH influence was removed by measuring the viscosity of $0.5 \mathrm{M}$ CED solution that contained $20 \mathrm{mg}$ of HT. Viscosity in that case was unaffected. The larger LDH-U particles may have a small effect on flow properties; but, further experiments need to be performed to determine the extent of this influence. One possibility for the polymer length reduction is that the $\mathrm{LDH}$ is acting as a catalyst during the alkaline hydrothermal treatment. Chemisorbed particles can catalyse reactions only at the imminent fiber surface. However, the Uhyd and lss processes may catalyse hydrolysis reactions within the fiber wall as well.

\subsubsection{Microrobotic Instrumentation}

Experimental values from the microrobotic platform are tabulated in Tables 4 and 5. Since the LDH-C and LDH-OH nucleated mainly on the fiber surface in $h s s$ and $l s s$ synthesis, respectively, the compliances should not change significantly. The degree of polymerisation of cellulose is inversly related to fiber stiffness. Reduction in cellulose polymer length should therefore increase fiber compliance. Albeit the standard deviations in the experimented values are large, one can, nevertheless, fathom the tendency that follows. Experimental results show that Uhyd synthesis route reduced the fibers flexibility about $50 \%$ while $l s s$ and $h s s$ synthesis routes leave fibers unchanged. The reduction in compliance was significant according to the $T$-test as well (Table 5). Therefore the LDH particles that adsorb onto the fibers external 
surface alone do not contribute to compliance in the given system. Particles that reside inside the fiber wall reduce compliance markedly.

Table 4. The experimental average compliances $\left(k^{-1}\right)$ for untreated Kraft pulp fibers (Reference) according to Saketi et al. [30], and, for pulp samples from this work are presented with cellulose fraction corrected limiting viscosity numbers $(\eta)$. Standard deviation for the compliances are indicated in the parentheses.

\begin{tabular}{ccc}
\hline \multirow{2}{*}{ Sample } & $\boldsymbol{k}^{-\mathbf{1}}$ & $\boldsymbol{\eta}$ \\
\cline { 2 - 3 } & $\mathbf{1 0}^{\mathbf{9}} \mathrm{N}^{-\mathbf{1}} \cdot \mathrm{m}^{-\mathbf{2}}$ & $\mathrm{mL} \cdot \mathrm{g}^{-\mathbf{1}}$ \\
\hline Reference & $7.63(6.93)$ & 923 \\
lss & $7.93(4.04)$ & 813 \\
hss & $8.70(4.21)$ & 868 \\
Uhyd & $4.30(1.71)$ & 754 \\
\hline
\end{tabular}

Table 5. The calculated $T$-test results $(t)$ for compliance measurements and the determined probability for rejection of null hypothesis (Null). High percentile value indicates greater statistical significance between the tested specimen pairs.

\begin{tabular}{ccc}
\hline Pair & $\boldsymbol{t}$ & Null (\%) \\
\hline Uhyd to $l s s$ & 2.6182 & 98.2 \\
Uhyd to $h s s$ & 3.0581 & 99.3 \\
lss to $h s s$ & 0.4163 & 31.8 \\
\hline
\end{tabular}

\subsubsection{Adsorption Experiments}

Most of the ionic groups in bleached Kraft pulp fibers originates from hexenuronic and 4- $O$-methylglucuronic acids in xylan side chains ([41,68], p. 734). Some carbonyl functionalities may reside in residual lignin as muconic acids but the number is low and their contribution to total charge may be small [69]. Fibers charge and their acid/base properties in general has been recognized to influence over many important parameters in pulp and paper manufacturing such as metal ion binding, fiber swelling and water uptake, sheet formation, tensile strength, refining response, and, floc formation together with retention aids $[32,51,70,71]$.

The results for adsorption isotherms with MB and MY are presented in Figure 10. The ionic strength in each experiment was set with $\mathrm{KCl}$ and kept at $1 \mathrm{mM}$. The solution $\mathrm{pH}(8.2)$ was controlled with barbital buffer. At this $\mathrm{pH}$ the fibres are partially swollen. Determined charge in reference pulp according to MB adsorption was approximately $50 \mu \mathrm{mol} \cdot \mathrm{g}^{-1}$ (Figure 10A). The LDH-C and LDH-OH particles reduced the adsorption of MB approximately $15 \%$ while $\mathrm{LDH}-\mathrm{U}$ provided $35 \%$ reduction. Langmuir fitted data indicates true monolayer formation and equal site preference for both probe molecules (Figure 10B,D). For MB adsorption the fitted parameters over estimates adsorption capacity $(n)$. The binding affinity term $(K)$ is similar to all modified pulp fibers while for the reference it is clearly higher (Figure 10A,B). In case 
of MY, the fitted parameters for equilibrium concentration followed the observed monolayer adsorption and $K$ decreased in the order hss $>$ Uhyd $>l s s$ (Figure 10C,D). The change in solvent ionic strength above approximately $5 \mathrm{mM}$ reduced adsorption significantly (Figure 10E). The adsorption phenomenon must, therefore, be controlled mainly by electrokinetic interactions. Also, the reference pulp fibers did not adsorb any MY. It seems that the more there is LDH on external fiber surface and the better the crystallinity is in LDH, the higher is the affinity towards anionic species. Induced crystalline defects, however, provide higher number of exchangeable anionic sites. These results suggest that major part of the carboxylic acids in pulp fibers are still free and that fibers have become ampholytic to a degree. The contributions from surface bound and fiber wall embedded LDH cannot be addressed at this point.
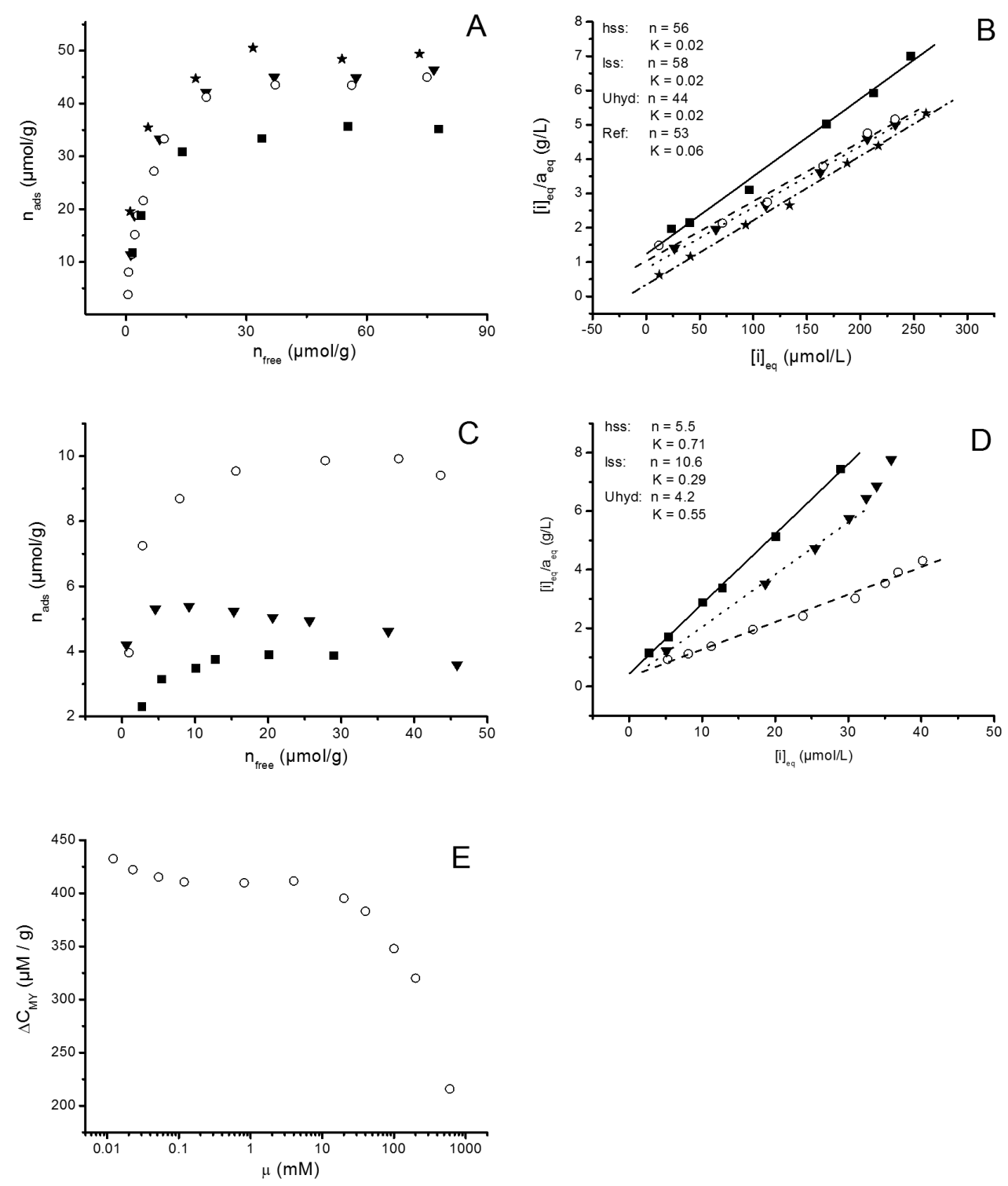

Figure 10. (A) Methylene Blue and (C) Metanil Yellow adsorption isotherms for fully bleached Kraft pulp reference ( $\star$ ), and LDH containing pulp samples (hss $(\boldsymbol{\nabla})$, lss $(\bigcirc)$, Uhyd ( $\mathbf{\square})$ ); (B The langmuir fit for methylene blue adsorption) and (D) for metanil yellow adsorption are also presented; (E) The effect of ionic strength on MY adsorption is shown with $l s s$ sample as an example. 


\section{Conclusions}

Effective LDH particle nucleation on fiber surface was succesfully conducted in aqueous medium of low super saturated $(l s s)$, high super saturated (hss) and slow urea hydrolysis (Uhyd) synthesis methods. In these synthesis procedures the applied pulp fibers were acting as templates for nano- $(70 \mathrm{~nm})$, sub-micron $(200 \mathrm{~nm})$ and micron $(2 \mu \mathrm{m})$ size LDH particles, respectively. The double layer structure of LDH was the outcome in all synthesis pathways.

Nucleation of LDH in situ from hss solvent with fully bleached Kraft pulp fibers in an autoclave does not induce particle synthesis or migration into the fiber wall, even if the fibers are fully saturated and swollen in alkaline medium $(\mathrm{pH}=10)$ and elevated temperature $\left(\mathrm{T}=120{ }^{\circ} \mathrm{C}\right)$. According to microrobotic experimentation the $\mathrm{LDH}$ that were bound to fibres external surface had a marginal effect on fiber flexibility. The synthesis via lss route resulted some particle migration into the fiber wall owing most likely to the stirring during the synthesis. However, majority of the nanoparticles remained on fiber surface. Considerable particle nucleation inside the fiber wall was discovered with TEM after hydrothermally induced urea hydrolysis (Uhyd) that resulted 50\% reduction in bending compliance. The nucleation within the cell wall was attributed to local $\mathrm{pH}$ change in $\mathrm{S} 2$ layer.

Significant reduction in specific exothermic heat was observed after each syntesis route. Reduction cellulose polymer length influenced to the heat of combustion during the first exotherm at around $593 \mathrm{~K}\left(320^{\circ} \mathrm{C}\right)$. Influence of LDH in enthalpy reduction was weight related.

Carboxylic acids are created in higher relative amounts during the slow combustion in comparison to rapid temperature increase that produces diones due, most likely, to simultaneous removal of water and hydroxyls from the LDH. The effect is amplified by the particles in fiber wall.

During the in situ synthesis the LDH were found to act as a catalyst in the depolymerisation reactions of cellulose in the alkaline aqueous solution. The cellulose polymerisation degree followed each synthesis in the order: hss $>$ lss $>$ Uhyd. The Uhyd had the greatest effect.

The LDH particles that were synthesised via lss method had the highest capacity for sulphate containing probe molecules while the better crystallised particles from hss and Uhyd had the highest affinity. Most of the acidic groups in cellulolse pulp fibers were free after LDH synthesis. Fibers had, therefore, become ampholytic after the modification.

Considering the results, we propose that these mineralised and surface modified fibers can be used in flame retardant, adsorbent applications and in systems where pulp fibers are modified in alkaline environment. If the catalytic activity of LDH is retained after nucleation inside the fibers cell wall there is also a possibility to modify fibers from within.

\section{Acknowledgments}

We would like to thank TEKES (Finnish Funding Agency for Technology and Innovation) for their financial support. We would also like to thank UPM-Kymmene, Stora Enso and Metsä Fiber for their financial support and Metsä Fiber Rauma mill for providing the pulp for the experiments. The research leading to these results has received funding from the WoodWisdom-Net 2 Research Programme in the project PowerBonds (Grant No.: 256527). Finally we acknowledge all the laboratory personnel at Åbo 
Akademi University who assisted in laboratory experimentation, especially Jessi Mäkinen and Xiaoman Yang for their help.

\section{Author Contributions}

TEM images were provided by Mehedi Reza (Aalto University, Finland) and the microrobotic experimentation was performed by Seyed Kourosh Latifi (Tampere University of Technology, Finland) under supervision of Pasi Kallio. Mika Lastusaari (University of Turku, Finland) helped with thermogravimetric analysis. Carl Lange carried out the study, as part of his Ph.D. thesis, and was responsible for all parts of the research project including writing the manuscript. Pedro Fardim was responsible for overall supervision.

\section{Supplementary Information}

Supplementary materials can be accessed at: http://www.mdpi.com/2079-6439/3/2/0103/s1.

\section{Conflicts of Interest}

The authors declare no conflict of interest.

\section{References}

1. Leroux, F.; Besse, J.P. Polymer Interleaved Layered Double Hydroxide: A New Emerging Class of Nanocomposites. Chem. Mater. 2001, 13, 3507-3515.

2. Basu, D.; Das, A.; Stoeckelhuber, K.W.; Wagenknecht, U.; Heinrich, G. Advances in layered double hydroxide (LDH)-based elastomer composites. Progress Polym. Sci. 2014, 39, 594-626.

3. Yu, X.Y.; Luo, T.; Jia, Y.; Xu, R.X.; Gao, C.; Zhang, Y.X.; Liu, J.H.; Huang, X.J. Three-dimensional hierarchical flower-like Mg-Al-layered double hydroxides: Highly efficient adsorbents for As(v) and Cr(vi) removal. Nanoscale 2012, 4, 3466-3474.

4. Zhou, J.Z.; Wu, Y.Y.; Liu, C.; Orpe, A.; Liu, Q.; Xu, Z.P.; Qian, G.R.; Qiao, S.Z. Effective Self-Purification of Polynary Metal Electroplating Wastewaters through Formation of Layered Double Hydroxides. Environ. Sci. Technol. 2010, 44, 8884-8890.

5. Mousty, C.; Walcarius, A. Electrochemically assisted deposition by local pH tuning: A versatile tool to generate ordered mesoporous silica thin films and layered double hydroxide materials. J. Solid State Electrochem. 2014, 1-27.

6. Ishizaki, T.; Chiba, S.; Watanabe, K.; Suzuki, H. Corrosion resistance of Mg-Al layered double hydroxide container-containing magnesium hydroxide films formed directly on magnesium alloy by chemical-free steam coating. J. Mater. Chem. A 2013, 1, 8968-8977.

7. Zhang, F.; Zhao, L.; Chen, H.; Xu, S.; Evans, D.; Duan, X. Corrosion Resistance of Superhydrophobic Layered Double Hydroxide Films on Aluminum. Angew. Chem. Int. Ed. 2008, 47, 2466-2469.

8. He, S.; An, Z.; Wei, M.; Evans, D.G.; Duan, X. Layered double hydroxide-based catalysts: Nanostructure design and catalytic performance. Chem. Commun. 2013, 49, 5912-5920. 
9. Parida, K.; Mohapatra, L. Recent progress in the development of carbonate-intercalated Zn/Cr LDH as a novel photocatalyst for hydrogen evolution aimed at the utilization of solar light. Dalton Trans. 2012, 41, 1173-1178.

10. Liu, J.; Li, Y.; Huang, X.; Li, G.; Li, Z. Layered Double Hydroxide Nano- and Microstructures Grown Directly on Metal Substrates and Their Calcined Products for Application as Li-Ion Battery Electrodes. Adv. Funct. Mater. 2008, 18, 1448-1458.

11. Faraji, S.; Ani, F.N. Microwave-assisted synthesis of metal oxide/hydroxide composite electrodes for high power supercapacitors-A review. J. Power Sour. 2014, 263, 338-360.

12. Fan, X.; Yang, Z.; Xie, X.; Long, W.; Wang, R.; Hou, Z. The electrochemical behaviors of Zn-Al-La-hydrotalcite in Zn-Ni secondary cells. J. Power Sour. 2013, 241, 404-409.

13. Goncalves, N.A.; Caio, T.R.N.; Boaventura de Moraes, S.; Lona, L.M.F. Synthesis and characterization of biodegradable poly(L-lactide)/layered double hydroxide nanocomposites. Polym. Bull. 2014, 71, 2235-2245.

14. Dou, Y.; Xu, S.; Liu, X.; Han, J.; Yan, H.; Wei, M.; Evans, D.G.; Duan, X. Transparent, Flexible Films Based on Layered Double Hydroxide/Cellulose Acetate wiht Excellent Oxygen Barrier Property. Adv. Funct. Mater. 2014, 24, 514-521.

15. Schmidt, B.; Katiyar, V.; Plackett, D.; Larsen, E.H.; Gerds, N.; Koch, C. Bender; Petersen, J.H. Migration of nanosized layered double hydroxide platelets from polylactide nanocomposite films. Food Addit. Contam. Part A Chem. Anal. Control Expo. Risk Assess. 2011, 28, 956-966.

16. Von Haartman, S.; Heikkilä, E.; Lange, C.; Fardim, P. Potential Applications of Hybrid Layered Double Hydroxide (LDH) Particles in Pulp and Paper Production. BioResources 2014, 9, 2274-2288.

17. Winters, R.; Schomaker, E.; de Vos, S.C. Polymer-Containing Composition, Its Preparation and Use. Netherlands WO2009112441 A1, 17 September 2009.

18. Beckham, G.T.; Biddy, M.J.; Chmely, S.C.; Sturgeon, M. Hydroxide Catalysts for Lignin Depolymerization. USA US 20140107381 A1, 17 April 2014.

19. Swanson, C.; Stimpfling, T.; Troutier-Thulliez, A.L.; Hintze-Bruening, H.; Leroux, F. Layered double hydroxide platelets exfoliation into a water-based polyester. J. Appl. Polym. Sci. 2013, 128, 2954-2960.

20. Costantino, U.; Marmottini, F.; Nocchetti, M.; Vivani, R. New Synthetic Routes to Hydrotalcite-Like Compounds: Characterisation and Properties of the Obtained Materials. Eur. J. Inorg. Chem. 1998, 1998, 1439-1446.

21. Mostafa Moujahid, E.; Besse, J.P.; Leroux, F. Poly(styrene sulfonate) layered double hydroxide nanocomposites. Stability and subsequent structural transformation with changes in temperature. J. Mater. Chem. 2003, 13, 258-264.

22. Abello, S.; Mitchell, S.; Santiago, M.; Stoica, G.; Perez-Ramirez, J. Perturbing the properties of layered double hydroxides by continuous coprecipitation with short residence time. J. Mater. Chem. 2010, 20, 5878-5887.

23. Wang, J.; Fan, G.; Li, F. A hybrid nanocomposite precursor route to synthesize dispersion-enhanced Ni catalysts for the selective hydrogenation of o-chloronitrobenzene. Catal. Sci. Technol. 2013, 3, 982-991. 
24. Abelló, S.; Bolshak, E.; Montané, D. Ni-Fe catalysts derived from hydrotalcite-like precursors for hydrogen production by ethanol steam reforming. Appl. Catal. A Gen. 2013, 450, 261-274.

25. Lin, J.K.; Uan, J.Y.; Wu, C.P.; Huang, H.H. Direct growth of oriented Mg-Fe layered double hydroxide $(\mathrm{LDH})$ on pure $\mathrm{Mg}$ substrates and in vitro corrosion and cell adhesion testing of LDH-coated Mg samples. J. Mater. Chem. 2011, 21, 5011-5020.

26. Ma, S.; Wang, J.; Du, L.; Fan, C.; Yahong, S.; Sun, Y.; Sun, G.; Yang, X. Co-Assembly of LDH Nanosheets with Crown Ethers: Structural Transformation and Water-Adsorption Behaviour. Eur. J. Inorg. Chem. 2013, 2013, 1363-1370.

27. He, J.; Wei, M.; Li, B.; Kang, Y.; Evans, D.G.; Duan, X. Preparation of Layered Double Hydroxides. In Layered Double Hydroxides; Duan, X., Evans, D.G., Eds.; Springer-Verlag: Berlin, Germany, 2006; Volume 119, pp. 90-103.

28. Lange, C.; Lundin, T.; Fardim, P. Hydrophobisation of mechanical pulp fibres with sodium dodecyl sulphate functionalised layered double hydroxide particles. Holzforschung 2011, 66, 433-441.

29. Lange, C.; Touaiti, F.; Fardim, P. Hybrid clay functionalized biofibres for composite applications. Compos. Part B Eng. 2013, 47, 260-266.

30. Saketi, P.; Treimanis, A.; Fardim, P.; Ronkanen, P.; Kallio, P. Microrobotic Platform for Manipulation and Flexibility Measurement of Individual Paper Fibres. In Proceedings of the IEEE/RSJ International Conference on Intelligent Robots and Systems, Taipei, Taiwan, 18-22 October 2010; pp. 5764-5766.

31. Martin, A. Toward a referee viscosity method for cellulose. Tappi J. 1951, 34, 363-366.

32. Fardim, P.; Holmbom, B. Fast determination of anionic groups in different pulp fibres by methylene blue sorption. TAPPI J. 2003, 2, 28-31.

33. Evans, D.G.; Slade, R.C. Structure and Bonding. In Layered Double Hydroxides; Duan, X., Evans, D.G., Eds.; Springer-Verlag: Berlin, Germany 2006; Volume 119, pp. 1-87.

34. Miyata, S. Physico-chemical properties of synthetic hydrotalcites in relation to composition. Clays Clay Miner. 1980, 28, 50-56.

35. Theiss, F.L.; Ayoko, G.A.; Frost, R.L. Thermogravimetric analysis of selected layered double hydroxides. J. Therm. Anal. Calorim. 2013, 112, 649-657.

36. Hibino, T.; Yamashita, Y.; Kosuge, K.; Tsunashima, A. Decarbonation behavior of Ma-Al-CO Hydrotalcite-like compounds during heat treatment. Clays Clay Miner. 1995, 43, 427-432.

37. Socrates, G. Infrared and Raman Characteristic Group Frequencies, 3rd ed.; John Wiley \& Sons, LTD: Chichester, England, 2004.

38. Stanimirova, T.; Hibino, T.; Balek, V. Thermal behhavior of $\mathrm{Mg}-\mathrm{Al}-\mathrm{CO}_{3}$ layered double hydroxide characterized by emanation thermal analysis. J. Therm. Anal. Calorim. 2006, 84, 473-478.

39. Adler, H.H.; Kerr, P.F. Infrared spectra, symmetry and structure rrelation of some carcarbon minerals. Am. Mineral. 1963, 48, 839-853.

40. Rey, F.; Fornés, V.; Rojo, J.M. Thermal decomposition of hydrotalcites. J. Chem. Soc. Faraday Trans. 1992, 88, 2233-2238.

41. Sixta, H. Pulp Properties and Applications. In Handbook of Pulp, Sixta H., Ed); WILEY-VCH Verlag GmbH\&Co.: Weinheim, Germany, 2006; Volume 1, pp. 1009-1067. 
42. Fan, G.; Xiang, X.; Fan, J.; Li, F. Template-assisted fabrication of macroporous $\mathrm{NiFe}_{2} \mathrm{O}_{4}$ films with tunable microstructural, magnetic and interfacial properties. J. Mater. Chem. 2010, 20, 7378-7385.

43. Stanimirova, T.; Balek, V. Characterization of layered double hydroxide $\mathrm{Mg}-\mathrm{Al}-\mathrm{CO}_{3}$ prepared by re-hydration of Mg-Al mixed oxide. J. Therm. Anal. Calorim. 2008, 94, 477-481.

44. Stone, J.; Scallan, A. The Effect of Component Removal upon the Porous Structure of the Cell Wall of Wood. Pulp Pap. Mag. Can. 1968, T288-T293.

45. Stone, J.; Scallan, A. A structural Model for the Cell Wall of Water-swollen Wood Pulp Fibres Based on Their Accessibility to Macromolecules. Cell. Chem. Technol. 1968, 2, 343-358.

46. Alince, B. Porosity of swollen pulp fibers revisited. Nord. Pulp Pap. Res. J. 2002, 17, 71-73.

47. Scallan, A. On Non-Solvent Water in Cellulosic Fibres as Determined by Salt Exclusion. Cell. Chem. Technol. 1987, 21, 215-223.

48. Yuichiro, S.; Takeshi, K. Swelling of pulp fibers in hot alkaline solution. Sen'i Gakkaishi 1962, $18,595-599$.

49. Gellerstedt, F; Wå gberg, L.; Gatenholm, P. Swelling behaviour of succinylated fibers. Cellulose 2000, 7, 67-86.

50. Teleman, A.; Harjunpää, V.; Tenkanen, M.; Buchert, J.; Hausalo, T.; Drakenberg, T.; Vuorinen, T. Characterisation of 4-deoxy- $\beta$-L-threo-hex-4-enopyranosyluronic acid attached to xylan in pine kraft pulp and pulpulp liquor by ${ }^{1} \mathrm{H}$ and ${ }^{13} \mathrm{CNMR}$ spectroscopy. Carbohydr. Res. 1995, 272, 55-71.

51. Susilo, R.; Chandraghatgi, R.; Li, X.S.; Englezos, P. Iron, manganese and copper equiligria with wood fibres in single salt aqueous suspensions. Can. J. Chem. Eng. 2005, 83, 537-547.

52. Eriksson, G.; Grén, U. Pulp washing: Sorption equilibria of metal ions on kraft pulps. Nord. Pulp Pap. Res. J. 1996, 11, 164-170.

53. Su, P.; Granholm, K.; Harju, L.; Ivaska, A. Determination of equilibrium constants for sorption of metal ions to pulp by a batch method. Nord. Pulp Pap. Res. J. 2013, 28, 521-528.

54. Andersson, R.; Liden, J.; Öhman, L.O. The Donnan theory applied to pulp washing-Experimental studies on the removal of anionic substances from an assumed fiber lumen volume and from the fiber wall. Nord. Pulp Pap. Res. J. 2003, 18, 405-412.

55. Towers, M.; Scallan, A. Predicting the ion-exchange of kraft pulps using Donnan theory. J. Pulp Pap. Sci. 1996, 22, J332-J337.

56. Koukkari, P.; Pajarre, R.; Pakarinen, H. Modeling of the ion exchange in pulp suspensions by Gibbs energy Minimization. J. Solut. Chem. 2002, 31, 627-638.

57. Li, X.S.; Englezos, P. Application of the NICA-Donnan approach to calculate equilibrium between proton and metal ions with lignocellulosic materials. J. Colloid Interface Sci. 2005, 281, 267-274.

58. Bygrave, G.; Englezos, P. A thermodynamics-based model and data for $\mathrm{Ca}, \mathrm{Mg}$ and $\mathrm{Na}$ ion partitioning in kraft pulp fibre suspensions. Nord. Pulp Pap. Res. J. 2000, 15, 155-159.

59. Athley, K.; Ulmgren, P. Interaction between divalent metal ions and oxygen-delignified kraft pulps. Nord. Pulp Pap. Res. J. 2001, 16, 204-214.

60. Yang, H.; Yan, R.; Chen, H.; Lee, D.H.; Zheng, C. Characteristics of hemicellulose, cellulose and lignin pyrolysis. Fuel 2007, 86, 1781-1788. 
61. Benítez-Guerrero, M.; López-Beceiro, J.; Sánchez-Jiménez, P.E.; Pascual-Cosp, J. Comparison of thermal behavior of natural and hot-washed sisal fibers based on their main components: Cellulose, xylan and lignin. TG-FTIR analysis of volatile products. Thermochim. Acta 2014, 581, 70-86.

62. Stølen, S.; Grønvold, F. Critical assessment of the enthalpy of fusion of metals used as enthalpy standards at moderate to high temperatures. Thermochim. Acta 1999, 327, 1-32.

63. Amigó, J.; Chanh, N. DTA study of thermal combustion of textile fibers. J. Therm. Anal. 1975, 7, 183-185.

64. Navirin Vhathvarothai, J.N.; Yu, J. An investigation of thermal behaviour of biomass and coal during co-combustion using thermogravimetric analysis (TGA). Int. J. Energy Res. 2013, $38,804-812$.

65. Ditmars, D.A. Calibration standards for differential scanning calorimetry I. Zinc: Absolute calorimetric measurement of $\mathrm{T}_{\text {fus }}$ and $\Delta_{\text {fus }} \mathrm{H}_{m}$. J. Chem. Thermodyn. 1990, 22, 639-651.

66. Zahra, C.; Zahra, A.M. The Perkin-Elmer 1020 series thermal analysis system. Thermochim. Acta 1996, 276, 161-174.

67. Lojewska, J.; Miśkowiec, P.; Lojewski, T.; Proniewicz, L.M. Cellulose oxidative and hydrolytic degradation: In situ FTIR approach. Polym. Degrad. Stab. 2005, 88, 512-520.

68. Dahlman, O.; Jacobs, A.; Liljenberg, A.; Olsson, A.I. Analysis of carbohydrates in wood and pulps employing enzymatic hydrolysis and subsequent capillary zone electrophoresis. J. Chromatogr. A 2000, 891, 157-174.

69. Chirat, C.; Hostachy, J.C.; Paloniemi, J.; Pelin, K.; Pohjanvesi, S.; Nordén, S.; Vesala, R.; Wennerström, M. Bleaching. In Papermaking Science and Technology, Chemical Pulping Part 1: Fibre Chemistry and Technology; Fardim P., Ed.; Paper Engineers Association/Paperi ja Puu Oy: Porvoo, Finland, 2011; Volume 6, p. 461.

70. Sundman, O.; Öhman, L.O. Acid/base and metal adsorption properties of CMC-type softwood Kraft ppulp of different charge. Nord. Pulp Pap. Res. J. 2006, 21, 372-381.

71. Barzyk, D.; Page, D.; Ragauskas, A. Acid Group Topochemistry and Fibre-to-Fibre Specific Bond Strength. J. Pulp Pap. Sci. 1997, 23, J59-J61.

(c) 2015 by the authors; licensee MDPI, Basel, Switzerland. This article is an open access article distributed under the terms and conditions of the Creative Commons Attribution license (http://creativecommons.org/licenses/by/4.0/). 